BNL-114567-2017-JA

\title{
Spinel Ferrite Core-Shell Nanostructures by a Versatile Solvothermal Seed-Mediated Growth Approach and Study of Their Nanointerfaces
}

\author{
M. S. Angotzi, H. L. Xin
}

Accepted by ACS Nano

July 2017

Center For Functional Nanomaterials

Brookhaven National Laboratory

\author{
U.S. Department of Energy \\ USDOE Office of Science (SC), \\ Basic Energy Sciences (SC-22)
}

Notice: This manuscript has been co-authored by employees of Brookhaven Science Associates, LLC under Contract No. DE-SC0012704 with the U.S. Department of Energy. The publisher by accepting the

manuscript for publication acknowledges that the United States Government retains a non-exclusive, paid-up, irrevocable, world-wide license to publish or reproduce the published form of this manuscript, or allow others to do so, for United States Government purposes. 


\section{DISCLAIMER}

This report was prepared as an account of work sponsored by an agency of the United States Government. Neither the United States Government nor any agency thereof, nor any of their employees, nor any of their contractors, subcontractors, or their employees, makes any warranty, express or implied, or assumes any legal liability or responsibility for the accuracy, completeness, or any third party's use or the results of such use of any information, apparatus, product, or process disclosed, or represents that its use would not infringe privately owned rights. Reference herein to any specific commercial product, process, or service by trade name, trademark, manufacturer, or otherwise, does not necessarily constitute or imply its endorsement, recommendation, or favoring by the United States Government or any agency thereof or its contractors or subcontractors. The views and opinions of authors expressed herein do not necessarily state or reflect those of the United States Government or any agency thereof. 


\title{
Spinel Ferrite Core-Shell Nanostructures by a Versatile Solvothermal Seed-Mediated Growth
} Approach and Study of Their Nanointerfaces.

Marco Sanna Angotzi, ${ }^{a b}$ Anna Musinu, ${ }^{a b}$ Valentina Mameli, ${ }^{a b}$ Andrea Ardu, ${ }^{a b c}$ Claudio Cara ${ }^{a b c}$

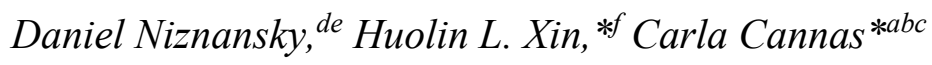

${ }^{a}$ Department of Chemical and Geological Sciences, Università di Cagliari, S.S. 554 bivio per Sestu, 09042, Monserrato (CA), Italy

${ }^{b}$ INSTM, Cagliari Unit

${ }^{\mathrm{c} C o n s o r z i o ~ A U S I, ~ P a l a z z o ~ B e l l a v i s t a ~ M o n t e p o n i, ~} 09016$ Iglesias, CI, Italy

${ }^{\mathrm{d}}$ Department of Inorganic Chemistry, Charles University of Prague, Czech Republic

eAS CR, Inst. Inorgan. Chem., vvi, Husinec Rez 25068, Czech Republic.

${ }_{\mathrm{f}}^{\mathrm{f}}$ enter for Functional Nanomaterials, Brookhaven National Laboratory, Upton, New York, United

States

\begin{abstract}
An easy, low-cost, repeatable seed-mediated growth approach in solvothermal condition has been proposed to synthesize bimagnetic spinel ferrite core-shell heterostructures in the $10-20 \mathrm{~nm}$ particle size range. Cobalt ferrite and manganese ferrite nanoparticles $\left(\mathrm{CoFe}_{2} \mathrm{O}_{4}\right.$ and $\left.\mathrm{MnFe}_{2} \mathrm{O}_{4}\right)$ have been coated with isostructural spinel ferrites like maghemite/magnetite, $\mathrm{MnFe}_{2} \mathrm{O}_{4}$ and $\mathrm{CoFe}_{2} \mathrm{O}_{4}$ with similar cell parameters to create different heterostructures. The conventional study of the structure, morphology and composition has been combined with advanced techniques in
\end{abstract}


order to achieve details on the interface at the nanoscale level. Clear evidences of the heterostructure formation have been obtained (i) indirectly by comparing the ${ }^{57} \mathrm{Fe}$ Mössbauer spectra of the core-shell samples and an ad-hoc mechanical mixture and (ii) directly by mapping the nanoparticles' chemical composition by electron energy loss spectroscopy (EELS) and energydispersive X-ray spectroscopy (EDX) in the scanning transmission electron microscopy mode (STEM). In addition, chemical-sensitive electron tomography in STEM-EDX mode has been applied in order to get detailed 3D images with a sub-nanometer spatial resolution.

\section{KEYWORDS}

core-shell, ferrite, EELS, EDX, Mössbauer, solvothermal, tomography

In recent years, magnetic nanoparticles with a core-shell heterostructure have been studied increasingly to combine the physical and chemical properties of different components to obtain multifunctional materials with a wide range of applications or to improve their performances. ${ }^{1-4}$ In this framework, bi-magnetic core-shell nanoparticles play a fundamental role because of the interactions arising from the contact of antiferromagnetic (AF), ferromagnetic (FM) and ferrimagnetic (FiM) phases. Since the discovery of the exchange bias phenomena by Meiklejohn and Bean, ${ }^{5}$ who prepared $\mathrm{Co} / \mathrm{CoO}$ core-shell nanoparticles by surface treatment, FM(or FiM)/AFM and AFM/FM(or FiM) couplings have been extensively studied. ${ }^{6-9}$ On the contrary, although the combination of magnetically hard and soft FM and FiM phases is of great interest for different applications (magnetic recording, permanent magnets, microwave absorption, biomedicine), these systems have been less explored. ${ }^{1}$ In this context, ideal crystalline phases to study this type of magnetic interaction are spinel ferrites $\left(\mathrm{M}^{\mathrm{II}} \mathrm{Fe}_{2} \mathrm{O}_{4}, \mathrm{M}^{\mathrm{II}}=\mathrm{Fe}^{2+}, \mathrm{Co}^{2+}, \mathrm{Mn}^{2+}, \mathrm{Ni}^{2+}\right.$, etc. $)$ which may have hard or soft magnetic nature depending on the type of divalent ion ${ }^{1,10-12}$ and can be easily 
prepared by a great variety of methods. ${ }^{10,13-17}$ For instance, cobalt ferrite, with a high magnetocrystalline anisotropy, shows a hard magnetic behaviour, while the isostructural manganese ferrite and spinel iron oxides (magnetite and maghemite) are magnetically soft phases. The main advantage of the use of isostructural phases is the possibility of an epitaxial growth of the shell around pre-existing seeds, with the so-called seed-mediated growth method. ${ }^{18-21}$ This two-step synthetic strategy represents a versatile approach to achieve well-defined heterostructures with controllable interfaces by changing size, shape, composition, and structure of the core and the precursors of the shell. In the literature, spinel ferrite core-shell nanoparticles ${ }^{18,22-28}$ with a low dispersity and high crystallinity have been mainly synthetized by the powerful high-temperature decomposition of acetylacetonates in the presence of surfactants. ${ }^{13}$ The necessity of more and more eco-friendly strategies, that use less amount of toxic organic solvents, less expensive precursors and lower temperatures, has moved the interest towards alternative synthetic approaches. Inexpensive and easy methods as coprecipitation ${ }^{29}$ and metal complex polymerization ${ }^{30,31}$ have been proposed in some specific cases but they do not allow a good control of the shell growth. Hydrothermal/solvothermal methods ${ }^{32}$ have in principle several advantages as the use of lowboiling and inexpensive solvents, the ease of the synthesis and the possibility to monitor pressure and temperature and a good repeatability. ${ }^{33-35}$ To the best of our knowledge, only a few examples are present in the literature for the synthesis of spinel ferrite core-shell heterostructures by these methods $\left(\mathrm{NiFe}_{2} \mathrm{O}_{4} @ \mathrm{CoFe}_{2} \mathrm{O}_{4}{ }^{36}\right.$ and $\left.\mathrm{CoFe}_{2} \mathrm{O}_{4} @ \mathrm{NiFe}_{2} \mathrm{O}_{4}\right),{ }^{37}$ but with results, in terms of products quality, far from those obtained in thermal decomposition conditions.

In this work, a seed-mediated growth approach in solvothermal conditions has been developed to synthesize core-shell nanoparticles made up of a hard magnetic phase $\left(\mathrm{CoFe}_{2} \mathrm{O}_{4}\right)$ and a soft one (Magnetite $\mathrm{Fe}_{3} \mathrm{O}_{4} /$ Maghemite $\gamma-\mathrm{Fe}_{2} \mathrm{O}_{3}, \mathrm{MnFe}_{2} \mathrm{O}_{4}$ ) with the same spinel structure, similar cell 
parameter and phase-contrast imaging. Clear evidences of the effective production of the coreshell structure have been obtained combining conventional techniques such as powder X-ray diffraction (XRD), transmission electron microscopy (TEM), induced coupled-plasma (ICP) and advanced ones (STEM-EELS, STEM-EDX, and STEM-EDX tomography) to map the chemical composition at the nanoscale. An indirect approach based on ${ }^{57} \mathrm{Fe}$ Mössbauer spectroscopy has been also used, allowing to demonstrate the potentiality of this technique for the study of coupled bimagnetic phases in heterostructures.

\section{RESULTS AND DISCUSSION}

Two samples of $\mathrm{CoFe}_{2} \mathrm{O}_{4}$ nanoparticles of different sizes, labelled as $\mathrm{Co} 1$ and $\mathrm{Co} 2$, and one sample of $\mathrm{MnFe}_{2} \mathrm{O}_{4}$, labelled as $\mathrm{Mn1}$, were prepared by solvothermal hydrolysis of mixed cobaltiron or manganese-iron oleates in a mixture of organic solvents with different polarities and water contents. The $\mathrm{Co} 1, \mathrm{Co} 2$ and $\mathrm{Mn} 1$ nanoparticles were used as seeds to produce core-shell nanostructures by means of a second solvothermal treatment (seed-mediated growth). In particular, for both $\mathrm{Co} 1$ and $\mathrm{Co} 2$, two core-shell samples were prepared with a shell of spinel iron oxide (maghemite/magnetite) and manganese ferrite, indicated as Cox@Fe and Cox@Mn (where x=1, 2), respectively. Moreover, two core-shell samples with a shell of cobalt ferrite and spinel iron oxide were prepared for sample Mn1, labelled as Mn1@Co and Mn1@Fe, respectively. The details about the synthesis are reported in the METHODS section.

Composition, structure and morphology. XRD patterns of the cores as well as the core-shell systems (Figure 1) show the typical reflections of a spinel phase. The cell parameters, $a$, for the samples Co1, Co2 and $\mathrm{Mn} 1$ are in good agreement with the value for the $\mathrm{CoFe}_{2} \mathrm{O}_{4}$ and $\mathrm{MnFe}_{2} \mathrm{O}_{4}$

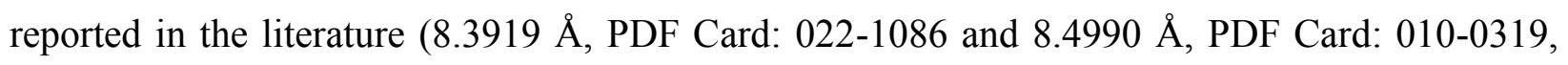


respectively). From the profile analysis, the average crystallite sizes have been estimated and are reported in Table 1.
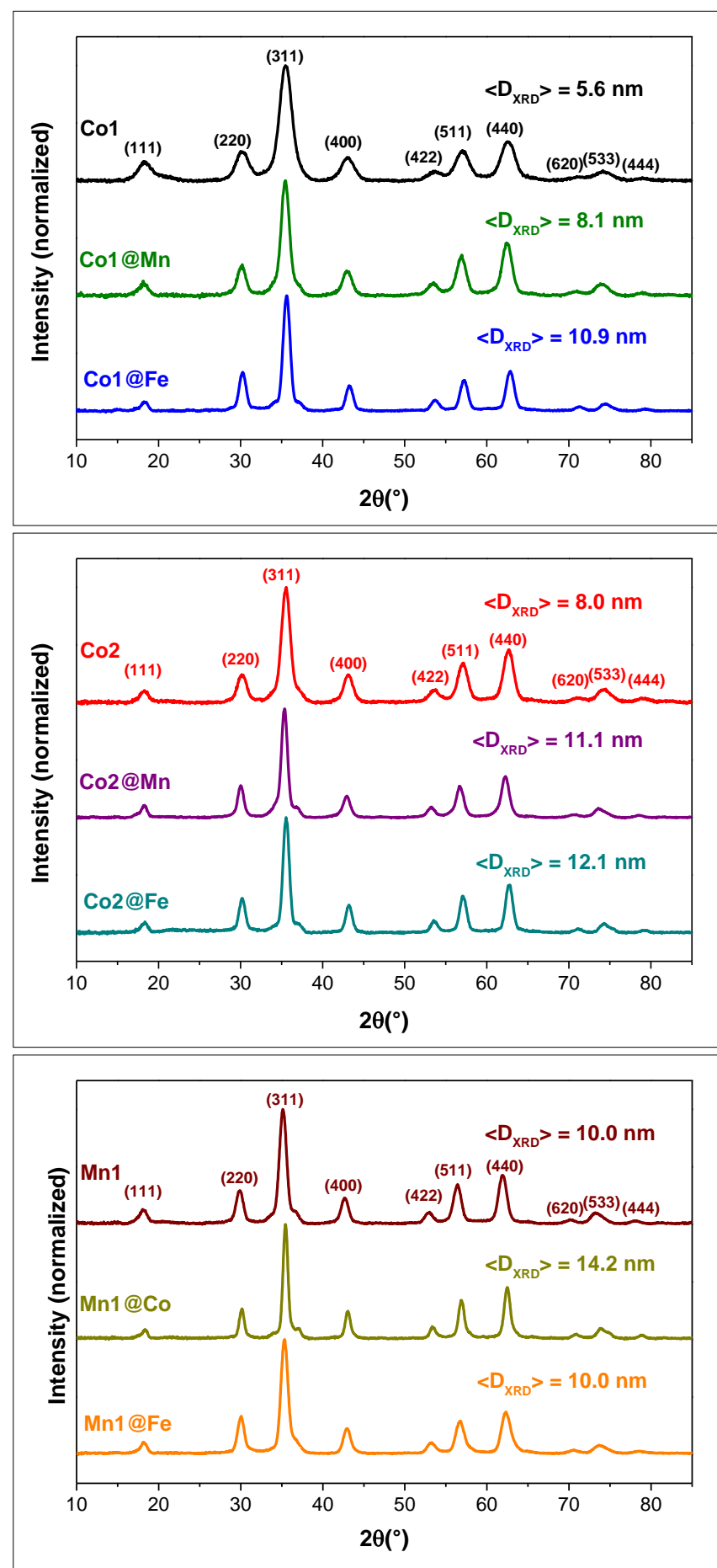

Figure 1. XRD Pattern of the samples. 


\begin{tabular}{|c|c|c|c|c|}
\hline Sample & $\mathbf{a}(\mathbf{\AA})$ & $\begin{array}{c}<\text { DXRD } \\
\mathbf{( n m})\end{array}$ & $\begin{array}{c}<\text { D } \\
\mathbf{( n m})\end{array}$ & $\begin{array}{c}\text { Organic phase } \\
\mathbf{( \% )}\end{array}$ \\
\hline $\mathrm{Co} 1$ & $8.39 \pm 0.01$ & $5.6 \pm 0.2$ & $5.4 \pm 0.9$ & 27 \\
\hline $\mathrm{Co1} @ \mathrm{Mn}$ & $8.40 \pm 0.02$ & $8.1 \pm 0.2$ & $9.4 \pm 1.0$ & 16 \\
\hline $\mathrm{Co1} @ \mathrm{Fe}$ & $8.36 \pm 0.01$ & $10.9 \pm 0.4$ & $10.5 \pm 1.2$ & 12 \\
\hline $\mathrm{Co} 2$ & $8.38 \pm 0.01$ & $8.0 \pm 0.2$ & $8.5 \pm 1.2$ & 20 \\
\hline $\mathrm{Co} 2 @ \mathrm{Mn}$ & $8.43 \pm 0.01$ & $11.1 \pm 0.7$ & $14.4 \pm 1.6$ & 8 \\
\hline $\mathrm{Co} 2 @ \mathrm{Fe}$ & $8.38 \pm 0.01$ & $12.2 \pm 0.8$ & $12.1 \pm 1.6$ & 10 \\
\hline $\mathrm{Mn} 1$ & $8.47 \pm 0.01$ & $10.0 \pm 0.2$ & $10.8 \pm 1.4$ & 8 \\
\hline $\mathrm{Mn} 1 @ \mathrm{Co}$ & $8.40 \pm 0.01$ & $14.2 \pm 0.8$ & $17.9 \pm 2.1$ & 9 \\
\hline $\mathrm{Mn} 1 @ \mathrm{Fe}$ & $8.42 \pm 0.01$ & $10.0 \pm 0.8$ & $11.1 \pm 1.4$ & 15 \\
\hline
\end{tabular}

Table 1. Cell parameter (a), Crystallite size $\left(<\mathrm{DXRD}_{\mathrm{XR}}>\right)$, Particle size $\left(<\mathrm{D}_{\mathrm{TEM}}>\right)$ and amount of Organic phase calculated from TGA of the samples.

A slight variation of the lattice parameter has been observed for some core-shell systems. An increase of the lattice parameter is observed in the case of Co1@Mn and Co2@Mn, in agreement with the higher value of cell parameter for manganese ferrite than that of cobalt ferrite. Inversely, a decrease of the lattice parameter is detected when the shell is made of spinel iron oxide. The core-shell samples Mn1@Co and Mn1@Fe are subjected to a decrease of the lattice parameter due to the presence of cobalt ferrite or spinel iron oxide, respectively. Concerning the crystallite size obtained from the experimental profile, all the core-shell samples are characterised by higher values than the cores (Table 1), suggesting that a growth process took place, except for the sample Mn1@Fe, where the crystallite size is the same as the core. This can be explained by the formation of an amorphous shell of spinel iron oxide around the pre-formed core or partial dissolution of the core surface. 
The TEM Bright Field images of the cores (Figure 2) show well-separated spheroidal nanoparticles with particle size similar to crystallite size, suggesting a high crystallinity of the particles (Table 1). Moreover, all the samples are characterised by narrow unimodal particles size distributions, with a dispersity in a 13-17\% range. TEM images of the core-shell samples, reported in Figure 2, show spherical particles with the presence of a unimodal size distribution and mean particle size higher than the core, suggesting that there has not been nucleation of new particles but the growing of the new phase around the pre-existing seeds, forming a core-shell heterostructure. This is also supported by the significant decrease of the dispersity with respect to the original core.
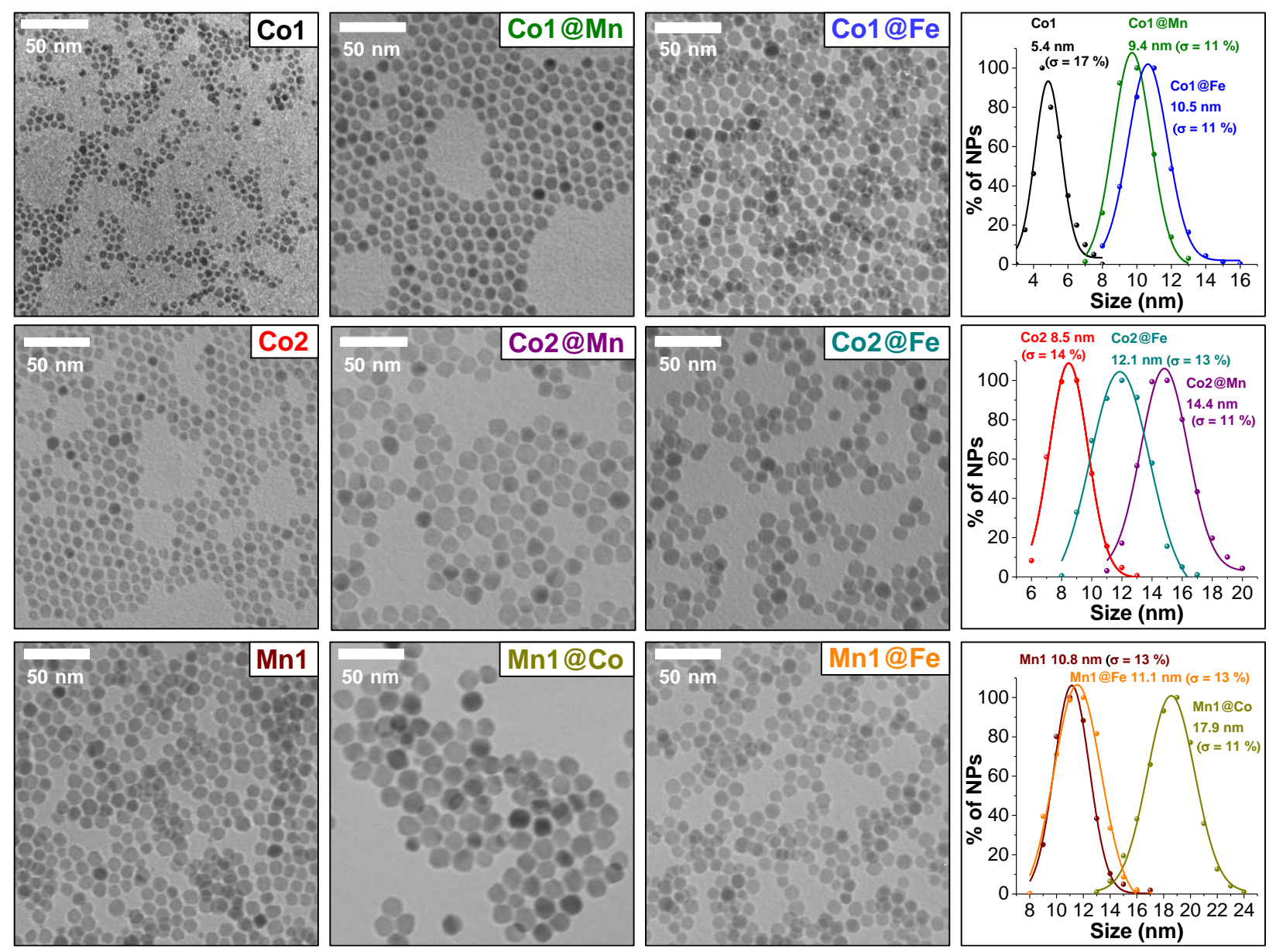

Figure 2. TEM Bright Field images and particle size distribution of the samples. 
A careful study by means of high resolution microscopy (HRTEM and HRSTEM) has been conducted on all the samples, showing highly crystalline particles with no evidences of any amorphous part or heterojunctions. Here, as an example, the images of Co1@Mn and Co2@Fe samples are shown in Figure 3. The interlayer distances confirm the presence of the spinel oxide phase in agreement with the XRD data. The core-shell samples show no lattice mismatch, suggesting an epitaxial coating on the respective cores. Unfortunately, due to the very similar phase-contrast imaging, even high resolution microscopy cannot distinguish the core from the shell.

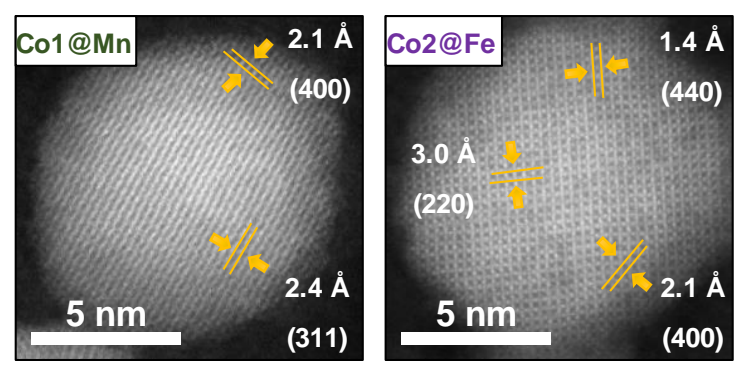

Figure 3. HRSTEM images of the Co1@Mn and Co2@Fe samples.

ICP analyses have been carried out on both core and core-shell systems. The $\mathrm{M}^{\mathrm{II}}: \mathrm{Fe}^{\mathrm{III}}\left(\mathrm{M}^{\mathrm{II}}=\right.$ $\mathrm{Co}^{2+}$ or $\mathrm{Mn}^{2+}$ ) molar ratio for $\mathrm{Co} 1, \mathrm{Co} 2$ and $\mathrm{Mn} 1$ samples have been found equal to $0.49,0.55$ and 0.50 , respectively, suggesting the formation of almost stoichiometric spinel ferrites. Taking into account the $\mathrm{M}^{\mathrm{II}}: \mathrm{Fe}^{\mathrm{III}}$ molar ratio found in the cores, it has been possible to roughly estimate the $\mathrm{M}^{\mathrm{II}}: \mathrm{Fe}^{\mathrm{III}}$ molar ratio in the shell, in the case of cobalt or manganese ferrite coating. Indeed, Co1@Mn,Co2@Mn and Mn1@Co samples present a $\mathrm{M}^{\mathrm{II}}: \mathrm{Fe}^{\mathrm{III}}$ molar ratio in the shell equal to $0.48,0.45$ and 0.64 , respectively which indicates the formation of an almost stoichiometric spinel ferrite shell. The empirical formulas are reported in Table 4S. 
The capping by oleate molecules has been demonstrated by FTIR (Figure 1S) and TGA (Figure 2S). FTIR spectra show the main vibrational modes associated with the oleate molecules linked at the surface of the nanoparticles, as the $\mathrm{COO}^{-}$vibrational modes $\left(v_{\mathrm{as}}\left(\mathrm{COO}^{-}\right), v_{\mathrm{s}}\left(\mathrm{COO}^{-}\right)\right)$and those ones related to the hydrocarbon chain. ${ }^{12,15}$ The complete assignment for all the samples is reported in Table 5S.

TGA curves, recorded under an oxygen atmosphere are shown in Figure 2S. The weight losses percentages obtained for the samples are reported in Table 1. A decrease of the organic content with increasing the nanoparticles' diameter has been observed. Indeed, as the size of the particles increases, the surface/volume ratio decreases, leading to a lower number of organic molecules able to cap the surface. The weight percentages correspond to a monolayer of oleate molecules surrounding the nanoparticle surface, as reported in the supporting information Table $\mathbf{6 S}$. These values are also really close to those reported by other authors for oleic acid-coated spinel iron oxides nanoparticles and suggest the presence of a close-packed monolayer of the capping agent. ${ }^{38-}$ 40

Evidence of heterostructure by RT Mössbauer spectroscopy. In this framework, ${ }^{57} \mathrm{Fe}$ Mössbauer spectroscopy has been used as complementary technique to study the structural and magnetic properties of spinel ferrites ${ }^{41-44}$ and as an alternative tool to evidence the bimagnetic core-shell heterostructures. Indeed, Mössbauer spectroscopy can discriminate the different iron state, being the isomer shift $(\delta)$ sensitive to the oxidation state of iron $\left(\mathrm{Fe}^{2+}, \mathrm{Fe}^{3+}\right.$ in spinels $)$ and the quadrupole splitting $\left(\Delta \mathrm{E}_{\mathrm{Q}}\right)$ sensitive to the different types of structural sites (octahedral and tetrahedral in spinels) and positions of neighbour ions, allowing for example to distinguish magnetite from maghemite and hematite to the other $\mathrm{Fe}_{2} \mathrm{O}_{3}$ polymorphs. Furthermore, information about the magnetic structure can be obtained from the hyperfine field $\left(\mathrm{B}_{\mathrm{hf}}\right)$ permitting to 
discriminate iron containing phases in the superparamagnetic (non-blocked) or ferromagnetic/antiferromagnetic state (blocked). The full width at half maximum (FWHM) of the subspectra is related to the distributions of particle size and to the distributions of the ${ }^{57} \mathrm{Fe}$ Mössbauer spectroscopy parameters. In detail, room temperature (RT) ${ }^{57} \mathrm{Fe}$ Mössbauer measurements have been carried out for all the samples (Figure 4) and the hyperfine parameters are shown in Table 2. Due to the strong overlap of signals at room temperature it is difficult to obtain unambiguous conclusions on phase and iron position in octahedral and tetrahedral sites. The discussion of Mössbauer spectra will be therefore oriented mainly on the evolution of magnetic properties manifested by hyperfine field.

The sample Co1 $\left(<\mathrm{DXRD}_{\mathrm{XR}}>=5.6 \mathrm{~nm}\right)$ shows a broad singlet associated with particles having a relaxation time near the Mössbauer measurement time window $\left(\tau_{\mathrm{M}}\right)$ accompanied with a sharper one related to the particles in the superparamagnetic state. The spectrum of the sample Co2 $\left(<\mathrm{D}_{\mathrm{XRD}}>=8.1 \mathrm{~nm}\right)$ is fitted by one sextet deriving from the overlapping at room temperature accounting for $\mathrm{Fe}^{\mathrm{III}}$ in the octahedral and tetrahedral sites of cobalt ferrite. The sample $\mathrm{Mn} 1$ $\left(<\mathrm{DXRD}_{\mathrm{X}}>=10.0 \mathrm{~nm}\right)$ shows a sharp singlet, which indicates the presence of nanoparticles in superparamagnetic state.

Clear differences can be evidenced by the comparison of the cores with the correspondent coreshell systems: the appearance of two sextets in place of singlets, indicating the formation of nanoparticles in the blocked state (Co1@Mn, Co1@Fe, Mn1@Co) and a separation of the two sextets (Co2@Mn, Co2@Fe). The two sextets can be due to two different spinel phases $\left(\mathrm{CoFe}_{2} \mathrm{O}_{4}\right.$ and $\mathrm{MnFe}_{2} \mathrm{O}_{4}$ or maghemite/magnetite) or to two different sublattices (octahedral and tetrahedral) in a spinel phase due to the formation of a single coherent structural domain, as observed by 
HRSTEM (Figure 3). The sample Mn1@Fe shows a collapsed sextet, due to the presence of nanoparticles in the edge between the superparamagnetic and the blocked state.

The isomer shift values for all the samples but Co2@ $\mathrm{Fe}$ are in the range of $\mathrm{Fe}^{\mathrm{III}}(0.28-0.39 \mathrm{~mm} / \mathrm{s})$, whereas Co2@Fe presents a higher isomer shift for one sextet (IS=0.50 mm/s), due to the presence of $\mathrm{Fe}^{\mathrm{II}}$, suggesting its not complete oxidation to $\mathrm{Fe}^{\mathrm{III}}$. The different behaviour with respect to the Co1@Fe is probably due to the reduced nanoparticle size that leads to a higher degree of oxidation of magnetite to maghemite. Nevertheless, since iron is present both in the core and in the shell, the evaluation of the amount of $\mathrm{Fe}^{\mathrm{II}}$ and $\mathrm{Fe}^{\mathrm{III}}$ in our samples is not trivial and the occurrence of $\mathrm{Fe}^{\mathrm{II}}$ cannot be completely excluded.

The hyperfine field values can be affected by the nature of the coating (manganese ferrite or spinel iron oxide) and the thickness of the shell (and consequently the final crystallite size). Specifically, Co1@Fe $(<\mathrm{DXRD}>=10.9 \mathrm{~nm})$ shows hyperfine fields for both sextets higher than Co1@Mn $\left(<\mathrm{D}_{\mathrm{XRD}}>=8.1 \mathrm{~nm}\right)$, as manganese ferrite and maghemite are expected to have anisotropy constants of the same magnitude (for bulk materials: $3 \cdot 10^{3} \mathrm{~J} / \mathrm{m}^{3}$ and $5 \cdot 10^{3} \mathrm{~J} / \mathrm{m}^{3}$, respectively), the bigger crystallite size of the particles of Co1@Fe $(10.9 \mathrm{~nm})$ seems to be primarily responsible for the higher hyperfine field values. On the contrary, Co2@Mn $\left(<\mathrm{D}_{\mathrm{XRD}}>=11.1 \mathrm{~nm}\right)$ and $\mathrm{Co} 2 @ \mathrm{Fe}(<\mathrm{DRD}>=12.2 \mathrm{~nm})$ have similar crystallite sizes and the increase in the hyperfine field values for the sample Co2@Fe can be due principally to the higher anisotropy constant of magnetite, that for bulk material is $1.3 \cdot 10^{4} \mathrm{~J} / \mathrm{m}^{3} .45$ The sample Mn1@Co $(<\mathrm{D}$ XRD $>=14.2 \mathrm{~nm})$ shows the highest hyperfine field values for both octahedral and tetrahedral sites, due to the big crystallite size and the presence of cobalt ferrite in the shell, which forms the $78 \%$ of the total nanoparticle volume. The sample Mn1@Fe shows lower hyperfine field values for both sites in comparisonwith Mn1@Co, being manganese ferrite and maghemite/magnetite two magnetically 
soft phases with respect to cobalt ferrite (which magnetocrystalline anisotropy in the bulk is $\left.2.9 \cdot 10^{5} \mathrm{~J} / \mathrm{m}^{3}\right)$. It is known that the $\mathrm{O}_{\mathrm{h}}-\mathrm{T}_{\mathrm{d}}$ exchange interactions $\left(J_{A B}\right)$ are stronger than $\mathrm{T}_{\mathrm{d}}-\mathrm{T}_{\mathrm{d}}$ ones $\left(J_{A A}\right)$ or $\mathrm{O}_{\mathrm{h}}-\mathrm{O}_{\mathrm{h}}$ ones $\left(J_{B B}\right)$. Therefore, the hyperfine field of the tetrahedral sublattice will be more affected by the cations located in the octahedral sublattice. ${ }^{46}$ In particular, for the Co2@Fe sample, the highest difference in the hyperfine field, with respect to the Co2@Mn sample, has been detected for $\mathrm{T}_{\mathrm{d}}$ sites, probably due to the presence of $\mathrm{Fe}^{\mathrm{II}}$ only in the $\mathrm{O}_{\mathrm{h}}$ sites. 

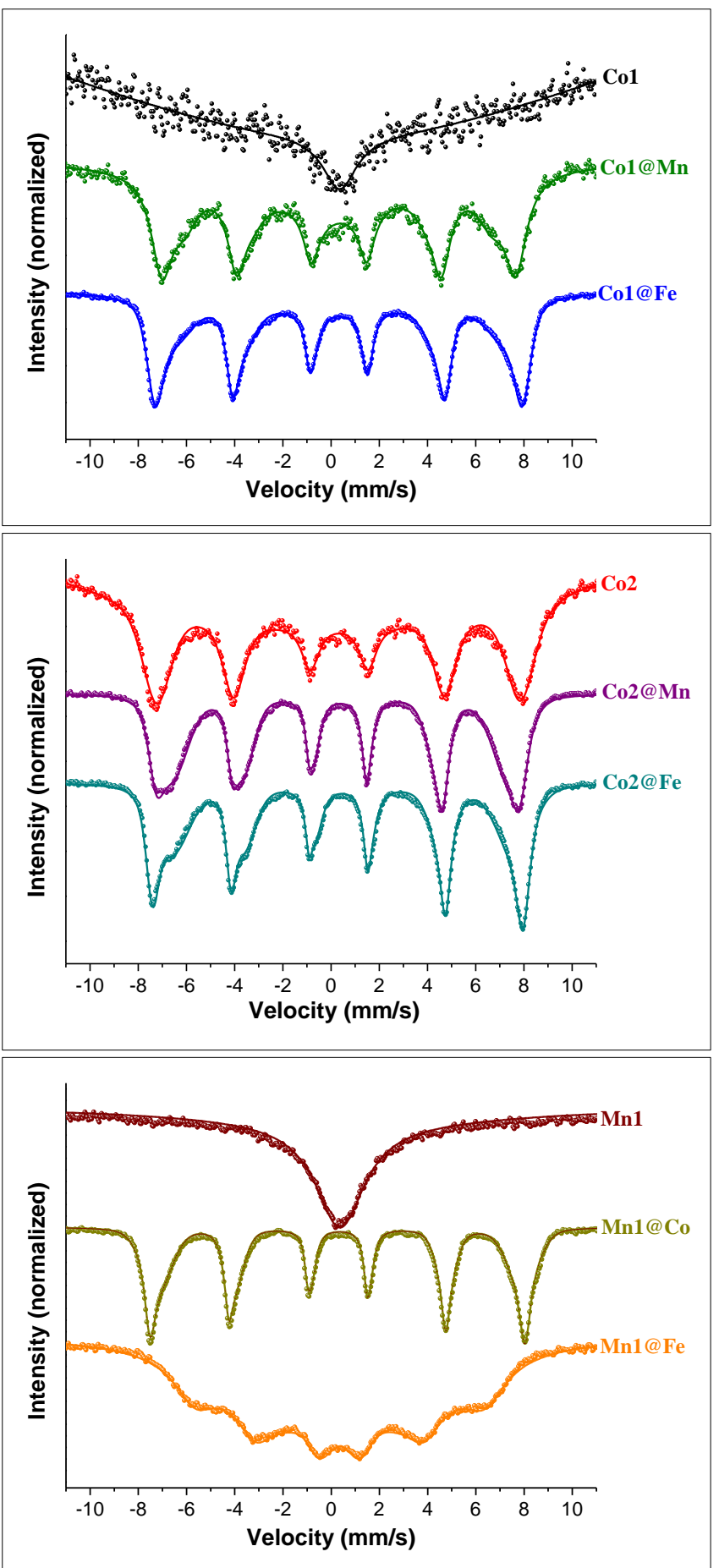

Figure 4. Room Temperature ${ }^{57} \mathrm{Fe}$ Mössbauer spectra of the samples. 


\begin{tabular}{|c|c|c|c|c|c|c|c|}
\hline & Type & $\begin{array}{l}\text { Size } \\
(\mathbf{n m})\end{array}$ & Signal & $\begin{array}{c}\boldsymbol{\delta} \\
(\mathbf{m m} / \mathbf{s})\end{array}$ & $\begin{array}{c}\Delta \mathrm{E}_{\mathrm{Q}} \\
(\mathrm{mm} / \mathrm{s})\end{array}$ & $\begin{array}{l}B_{\text {hf }} \\
(T)\end{array}$ & $\begin{array}{c}\text { FWHM } \\
(\mathrm{mm} / \mathrm{s})\end{array}$ \\
\hline \multirow[t]{2}{*}{ Co1 } & \multirow[t]{2}{*}{$\mathrm{CoFe}_{2} \mathrm{O}_{4}$} & \multirow[t]{2}{*}{$5.6 \pm 0.2$} & Singlet & $0.2(1)$ & - & - & $12(1)$ \\
\hline & & & Singlet & $0.44(6)$ & - & - & $1.1(2)$ \\
\hline \multirow[t]{2}{*}{ Co1@Mn } & \multirow[t]{2}{*}{$\mathrm{CoFe}_{2} \mathrm{O}_{4} @ \mathrm{MnFe}_{2} \mathrm{O}_{4}$} & \multirow[t]{2}{*}{$8.1 \pm 0.2$} & Sextet & $0.34(2)$ & $\begin{array}{c}- \\
0.10(1)\end{array}$ & $39.7(2)$ & $1.56(5)$ \\
\hline & & & Sextet & $0.32(1)$ & $0.00(1)$ & $45.8(1)$ & $0.67(2)$ \\
\hline \multirow[t]{2}{*}{$\mathrm{Co} 1 @ \mathrm{Fe}$} & \multirow[t]{2}{*}{$\begin{array}{l}\mathrm{CoFe}_{2} \mathrm{O}_{4} @ \gamma- \\
\mathrm{Fe}_{2} \mathrm{O}_{3} / \mathrm{Fe}_{3} \mathrm{O}_{4}\end{array}$} & \multirow[t]{2}{*}{$10.9 \pm 0.4$} & Sextet & $0.35(1)$ & $\begin{array}{c}- \\
0.02(1)\end{array}$ & $42.4(2)$ & $0.64(1)$ \\
\hline & & & Sextet & $0.32(1)$ & $0.01(1)$ & $47.3(1)$ & $0.47(1)$ \\
\hline $\mathrm{Co} 2$ & $\mathrm{CoFe}_{2} \mathrm{O}_{4}$ & $8.0 \pm 0.2$ & Sextet & $0.32(1)$ & $\begin{array}{c}- \\
0.02(1)\end{array}$ & $46.9(1)$ & $0.87(2)$ \\
\hline \multirow[t]{2}{*}{ Co2@Mn } & \multirow[t]{2}{*}{$\mathrm{CoFe}_{2} \mathrm{O}_{4} @ \mathrm{MnFe}_{2} \mathrm{O}_{4}$} & \multirow[t]{2}{*}{$11.1 \pm 0.7$} & Sextet & $0.39(1)$ & $\begin{array}{c}- \\
0.02(1)\end{array}$ & 43.4(1) & $0.55(1)$ \\
\hline & & & Sextet & $0.28(1)$ & $0.01(1)$ & $46.9(1)$ & $0.28(1)$ \\
\hline \multirow[t]{2}{*}{$\mathrm{Co} 2 @ \mathrm{Fe}$} & \multirow{2}{*}{$\begin{array}{l}\mathrm{CoFe}_{2} \mathrm{O}_{4} @ \gamma- \\
\mathrm{Fe}_{2} \mathrm{O}_{3} / \mathrm{Fe}_{3} \mathrm{O}_{4}\end{array}$} & \multirow[t]{2}{*}{$12.2 \pm 0.8$} & Sextet & $0.50(1)$ & $0.00(1)$ & $43.9(1)$ & $0.64(1)$ \\
\hline & & & Sextet & $0.29(1)$ & $\begin{array}{c}- \\
0.02(1)\end{array}$ & $47.8(1)$ & $0.34(1)$ \\
\hline Mn1 & $\mathrm{MnFe}_{2} \mathrm{O}_{4}$ & $10.0 \pm 0.2$ & Singlet & $0.37(1)$ & - & - & $2.8(1)$ \\
\hline \multirow[t]{2}{*}{ Mn1@Co } & \multirow[t]{2}{*}{$\mathrm{MnFe}_{2} \mathrm{O}_{4} @ \mathrm{CoFe}_{2} \mathrm{O}_{4}$} & \multirow[t]{2}{*}{$14.2 \pm 0.8$} & Sextet & $0.37(2)$ & $\begin{array}{c}- \\
0.01(2)\end{array}$ & 47.1(1) & $0.41(2)$ \\
\hline & & & Sextet & $0.26(1)$ & $0.01(1)$ & $48.3(1)$ & $0.29(1)$ \\
\hline \multirow[t]{2}{*}{ Mn1@Fe } & \multirow{2}{*}{$\begin{array}{l}\mathrm{MnFe}_{2} \mathrm{O}_{4} @ \gamma- \\
\mathrm{Fe}_{2} \mathrm{O}_{3} / \mathrm{Fe}_{3} \mathrm{O}_{4}\end{array}$} & \multirow[t]{2}{*}{$10.0 \pm 0.8$} & Sextet & $0.39(1)$ & $0.03(1)$ & $24.8(1)$ & $1.00(1)$ \\
\hline & & & Sextet & $0.35(2)$ & $0.01(2)$ & $37.5(2)$ & $1.04(2)$ \\
\hline
\end{tabular}

Table 2. Room Temperature ${ }^{57} \mathrm{Fe}$ Mössbauer parameters of the samples: values of the isomer shift $(\delta)$, quadrupole splitting $\left(\Delta \mathrm{E}_{\mathrm{Q}}\right)$, hyperfine field $\left(\mathrm{B}_{\mathrm{hf}}\right)$, full width at half maximum (FWHM) of the components. 
As it has been said so far, the understanding of the core-shell heterostructure is not trivial, due to the same spinel crystallographic structure, similar cell parameter and phase-contrast imaging of the two counterparts. In order to verify if a core-shell structure was obtained, a reference sample (CoMn_R) made from a physical mixture of cobalt ferrite (Co_R) and manganese ferrite (Mn_R) nanoparticles in a mass ratio 1:1 was prepared and analysed. The nanoparticles were synthesised by the same procedure reported in the METHODS section, resulting in a crystallite size of about 8.7 nm for both Co_R and Mn_R samples, similar to the Co1@Mn (8.1 nm) sample. In the physical mixture, the oleate molecules that surround the particles should hinder the direct contact of the two magnetic phases. Figure 5 shows RT Mössbauer spectra of two different cores (Co_R, Mn_R), the physical mixture (CoMn_R) and the core-shell nanoparticles (Co1@Mn). Table 3 shows Mössbauer parameters for all these samples. The sample Co_R has been fitted with one sextet and one singlet, that correspond to nanoparticles in the blocked state (sextet) and those with a relaxation time close to the measurement time scale (singlet). In the case of the sample Mn_R, only two singlets have been adopted to fit the spectrum, indicating a distribution of hyperfine field values of the particles in the superparamagnetic state. The spectrum of the mixture (CoMn_R) has been fitted using two subspectra (one sextet and one singlet) upon the consideration that the sum of the individual three singlets (found in Co_R and $\mathrm{Mn} \_\mathrm{R}$ ) could result in just one singlet representing a distribution of hyperfine field of both samples. The sextet of the sample CoMn_R has the same parameters as the one of Co_R, indicating that there are no interparticle interactions. The singlet has isomer shift in the range typical for $\mathrm{Fe}^{\mathrm{III}}$ and it can be associated with superparamagnetic ferrite nanoparticles, mostly present in Mn_R. On the contrary, the spectrum of core-shell nanoparticles (Co1@Mn) shows two sextets with values of hyperfine fields equal to $39.7 \mathrm{~T}$ and $45.8 \mathrm{~T}$, which differ from the values found for cobalt ferrite or the physical mixture $(47.3 \mathrm{~T})$. Furthermore, no 
singlet can be found in the spectrum, indicating the absence of nanoparticles in the superparamagnetic state, that are found in CoMn_R. This comparison permits to exclude the independent formation of two phases $\left(\mathrm{CoFe}_{2} \mathrm{O}_{4}\right.$ and $\left.\mathrm{MnFe}_{2} \mathrm{O}_{4}\right)$ with similar size and can be considered as an indirect proof that the two magnetic phases in the sample Co1@Mn are in a close contact. This is in agreement with TEM data that evidence the formation of a monomodal distribution of the particles and HRSTEM that evidence a single crystal structure (Figure 3). To summarize, the Mössbauer approach suggests that the two counterparts, i.e. the soft manganese ferrite phase and the hard cobalt ferrite phase, are in contact and magnetically coupled, and behave like an individual system. However, to affirm that a core-shell architecture has been obtained, evidences from direct chemical mapping techniques and other indirect techniques are necessary. 

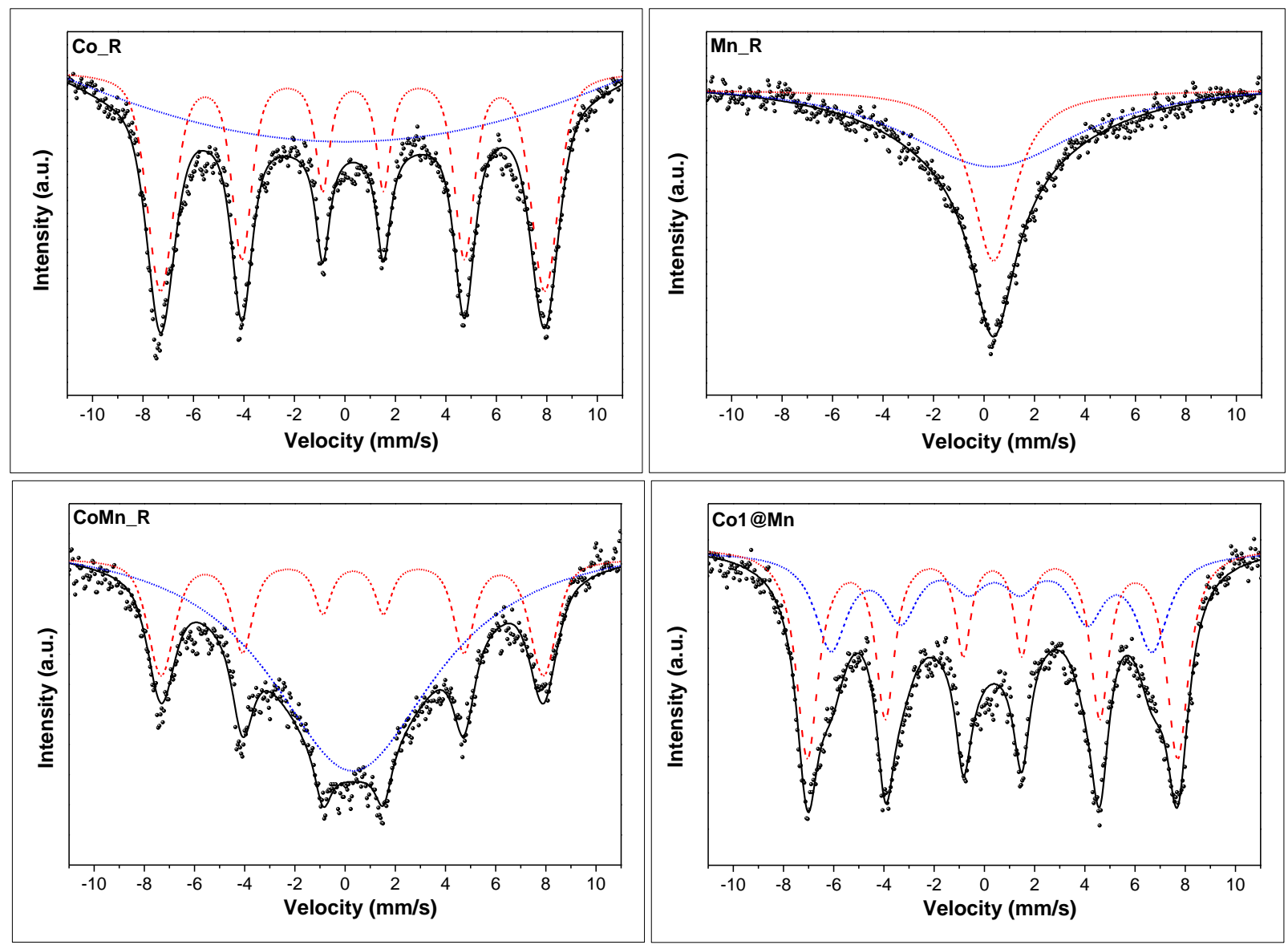

Figure 5. Room Temperature ${ }^{57} \mathrm{Fe}$ Mössbauer spectra of Co_R, Mn_R, CoMn_R and Co1@Mn.

\begin{tabular}{|c|c|c|c|c|c|c|c|}
\hline Sample & Type & Size (nm) & Signal & $\begin{array}{c}\boldsymbol{\delta} \\
(\mathbf{m m} / \mathbf{s})\end{array}$ & $\begin{array}{c}\Delta \mathbf{E}_{\mathbf{Q}} \\
(\mathbf{m m} / \mathbf{s})\end{array}$ & $\begin{array}{c}\mathbf{B}_{\text {hf }} \\
(\mathbf{T})\end{array}$ & $\begin{array}{c}\text { FWHM } \\
(\mathbf{m m} / \mathbf{s})\end{array}$ \\
\hline $\mathrm{Co} \_\mathrm{R}$ & $\mathrm{CoFe}_{2} \mathrm{O}_{4}$ & $8.7 \pm 0.3$ & Sextet & $0.32(1)$ & $-0.02(1)$ & $47.3(1)$ & $0.65(2)$ \\
\hline $\mathrm{Mn} \_\mathrm{R}$ & $\mathrm{MnFe}_{2} \mathrm{O}_{4}$ & $8.7 \pm 0.5$ & Singlet & $0.32(6)$ & - & - & $8(1)$ \\
\cline { 5 - 8 } & & & Singlet & $0.38(2)$ & - & - & $2.1(1)$ \\
\hline $\mathrm{CoMn} \_\mathrm{R}$ & $\mathrm{CoFe}_{2} \mathrm{O}_{4}+\mathrm{MnFe}_{2} \mathrm{O}_{4}$ & $8.0 \pm 0.5$ & Singlet & $0.31(3)$ & - & - & $8.1(1)$ \\
\cline { 4 - 8 } & & & Sextet & $0.30(1)$ & $-0.04(2)$ & $47.3(1)$ & $0.80(2)$ \\
\hline $\mathrm{Co1} @ \mathrm{Mn}$ & $\mathrm{CoFe}_{2} \mathrm{O}_{4} @ \mathrm{MnFe}_{2} \mathrm{O}_{4}$ & $8.1 \pm 0.2$ & Sextet & $0.34(2)$ & $-0.10(1)$ & $39.7(2)$ & $1.56(5)$ \\
\cline { 4 - 8 } & & & Sextet & $0.32(1)$ & $0.00(1)$ & $45.8(1)$ & $0.67(2)$ \\
\hline
\end{tabular}


Table 3. Room Temperature ${ }^{57} \mathrm{Fe}$ Mössbauer parameters of Co_R, Mn_R, CoMn_R and Co1@Mn: values of the isomer shift $(\delta)$, quadrupole splitting $\left(\Delta \mathrm{E}_{\mathrm{Q}}\right)$, hyperfine field $\left(\mathrm{B}_{\mathrm{hf}}\right)$, full width at half maximum (FWHM) of the components.

Chemical mapping at the nanoscale. It is worth noting that in order to have a direct and unambiguous prove of the formation of core-shell heterostructures, chemical mapping at the nanoscale is mandatory. ${ }^{47-49}$ Consequently, STEM-EDX, STEM-EDX tomography, STEM-EELS (for the Cox@Me samples) mapping of Fe, Co and Mn elements have been carried out. In the literature, only EELS ${ }^{18,24,25,28,36}$ is generally adopted to make chemical mapping at the nanoscale and there are no examples of the combined use of the two techniques. Thanks to the recent substantial technological progresses of energy-dispersive X-ray spectroscopy, in particular the development of ultrasensitive detectors (Super-X $\mathrm{X}^{\mathrm{TM}}$ detector with multiple silicon drift detectors), ${ }^{50-52}$ high-quality EDX maps ${ }^{53}$ and a detailed comparison between EDX and EELS is here presented in order to strength our findings about the creation of a core-shell heterostructure.

Figure 6 shows STEM-EDX and STEM-EELS chemical mapping, the corresponding line profiles of the samples and, as an example, an EDX and EELS spectrum for the Co2@Mn sample. All the cores (Co1, Co2 and Mn1) show homogenous distribution of $\mathrm{Co}$ (or $\mathrm{Mn}$ ) and Fe throughout the particles, with a $\mathrm{M}^{\mathrm{II}}: \mathrm{Fe}^{\mathrm{III}}\left(\mathrm{M}^{\mathrm{II}}=\mathrm{Co}^{2+}\right.$ or $\left.\mathrm{Mn}^{2+}\right)$ ratio, calculated from $\mathrm{EDX}$ data, equal to 0.56 , 0.59 and 0.48 , respectively. These values are in good agreement with the ICP data, suggesting the formation of almost stoichiometric ferrites and highlighting the reliability of the quantitative elemental mapping by STEM-EDX at the nanoscale. ${ }^{54}$ STEM-EDX chemical mapping of the coreshell samples unambiguously indicates the formation of a core-shell heterostructure. The single particle line profile calculated from EDX data reveals that the amount of Co (in case of Co1@Fe, Co1@Mn, Co2@Fe and Co2@Mn) or Mn (in case of Mn1@Fe and Mn1@Co) decreases 
gradually up to the interface. This behaviour, already observed, ${ }^{18,28}$ can be explained by technical or chemical effects. First of all, the chemical mapping has been done in transmission mode, so on 2D projections of spheroidal nanoparticles. Only ideal objects as perfect spheres with a perfect core-shell structure lead to not-overlapped core and shell compositional profiles. Indeed, for real samples, shape imperfections in the three-dimensional particle will result in a misrepresented onedimensional profile, being the average of several sections all over the particle $\left(360^{\circ}\right)$. It is known that the high temperature and acid condition ${ }^{55,29}$ can induce a partial dissolution of the nanoparticles, therefore, during the seed-mediated growth treatment, there might be a slight dissolution of the core surface, leading to a mixed chemical composition in the interface. However, in our case, i.e. mild temperature $\left(220^{\circ} \mathrm{C}\right)$ and non-acid condition, the dissolution phenomena are limited.

Being aware of the projection limits (2D images and 1D line profiles), STEM-EDX tomography has been performed on the Co2@Fe sample and the three-dimensional reconstruction of the Co and Fe distributions are shown in Figure 7 and Movie 1. These results have permitted to visualize the core-shell heterostructure, pointing out the 3D details: a sharp interface, spheroidal shape of the particle and homogenous coating of the shell around the well-centred core, i.e. with a uniform shell thickness.

STEM-EELS analyses have been carried out on the cobalt ferrite-based core-shell samples (Co1@Fe, Co1@Mn, Co2@Fe and Co2@Mn); the chemical mapping and the single particle line profile show the same tendency of the STEM-EDX maps. Considering the wide and established use of the electron energy loss spectroscopy, this study reveals that the energy-dispersive $\mathrm{x}$-ray spectroscopy provides a powerful approach to investigate core-shell heterostructures with a subnanometer spatial resolution. ${ }^{53}$ 
The shell thickness has been calculated from the chemical maps and are reported in Table 4S. The values correspond quite well to those ones calculated by conventional TEM as difference between core and core-shell diameters, and are between 2-3 nm, except for the samples having manganese ferrite as core. Taking into account the ICP data (Table 4S) and the shell thickness calculated from different techniques, it is possible to extract some information about the growth phenomena. The results obtained for the core-shell samples having cobalt ferrite as core are in agreement with the hypothesis of a homogenous growth of a stoichiometric spinel ferrite shell, also supported from ICP data. On the contrary, the difference between the shell thickness values in the samples having manganese ferrite as core could be interpreted by a slight dissolution of the core that lead to a smaller core size in the core-shell samples, in agreement with other authors reports for manganese ferrite in basic condition. ${ }^{56,57}$ ICP data showing a non-stochiometric cobalt ferrite shell formula in Mn1@Co support this picture. This may suggest differences in the growth mechanisms depending on the seeds material.

On the basis of above findings, thanks to the direct (chemical mapping at the nanoscale) and indirect approach (multitechnique analyses by the comparison with a mechanical mixture), the achievement of core-shell heterostructures has been proven. 

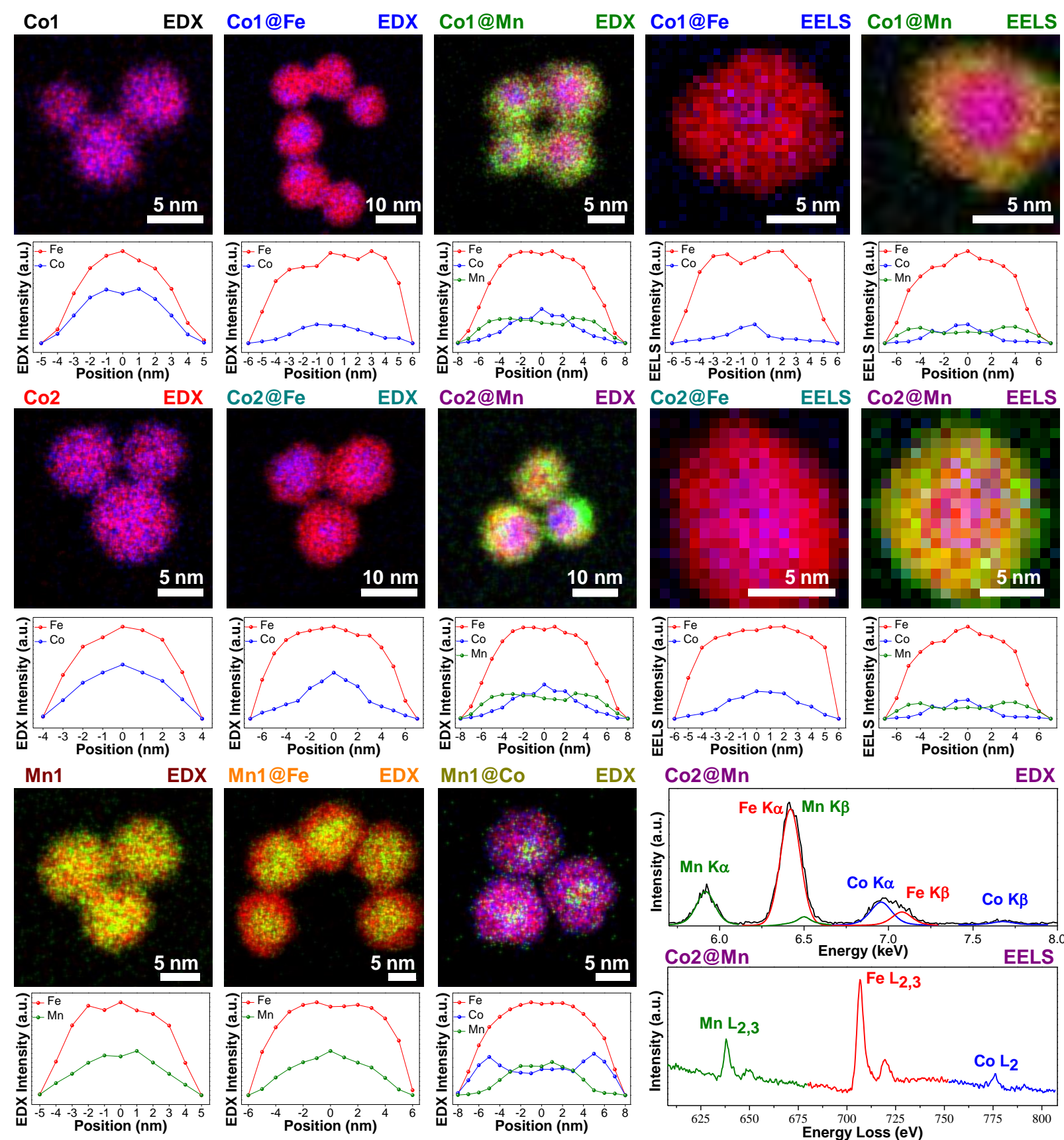

Figure 6. STEM-EDX and STEM-EELS mapping of the particles. EDX and EELS images are shown on top of the line profile across the samples. Cobalt is represented in blue, manganese in green, iron in red. Bottom right, two examples of EDX and EELS spectra collected for the Co2@Mn sample. 


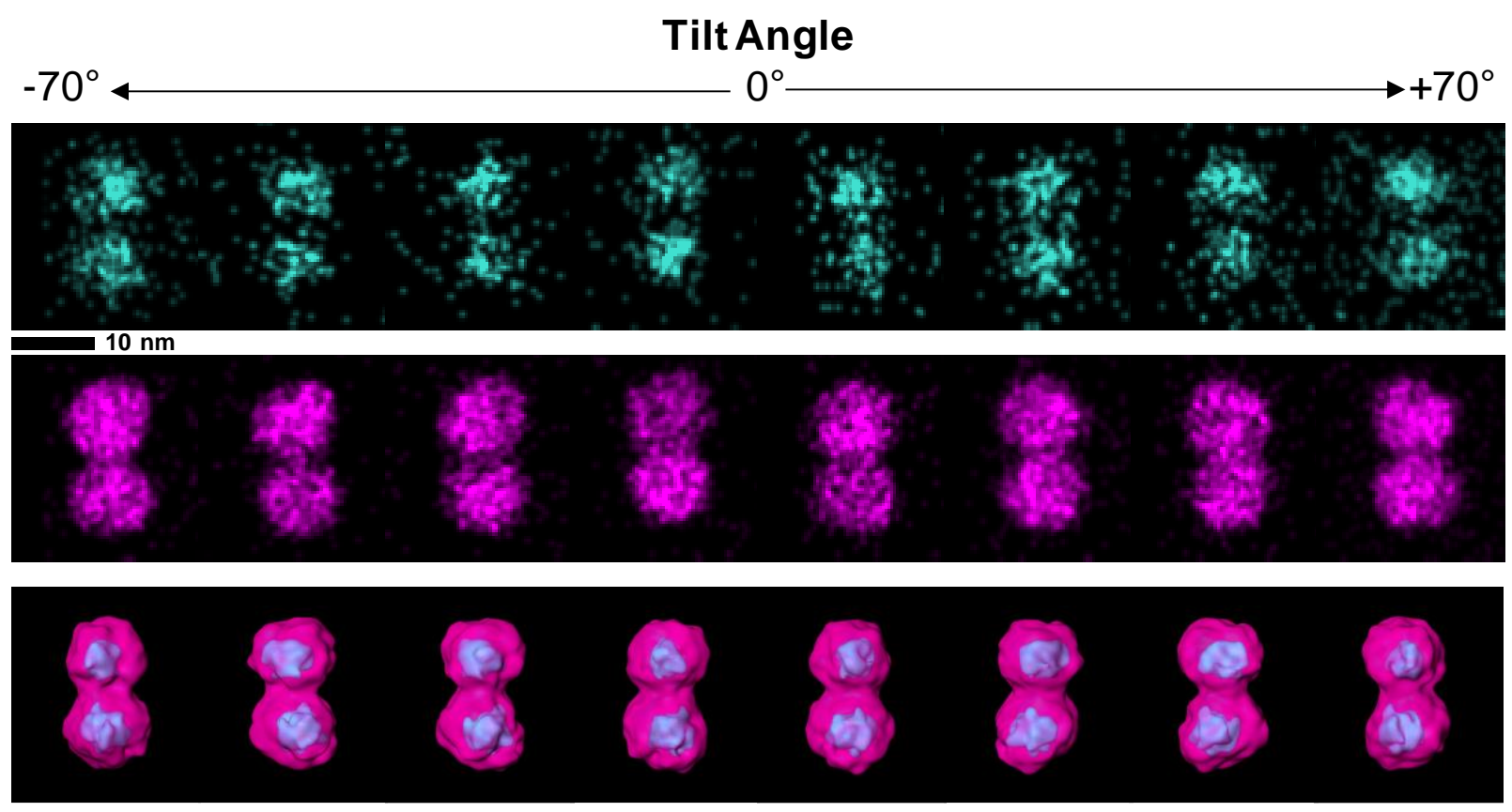

Figure 7. STEM-EDX tomography of the Co2@Fe sample. Top two rows show the projected distribution of Co and Fe mapped by STEM-EDX and the third row shows the isosurface rendition of the 3D distributions of Co and Fe in two touching Co2@Fe particles.

\section{CONCLUSIONS}

A simple, low-cost seed-mediated growth strategy in solvothermal condition is proposed to synthesize hydrophobic bimagnetic spinel ferrite core-shell nanoparticles. Conventional techniques (XRD, TEM, HRTEM/HRSTEM, TGA, FTIR, ICP) show for all the samples a single crystal domain, spherical shape, low dispersity and a monolayer of oleate molecules as the nanoparticles' capping. The higher particle size and lower dispersity than the core are indirect clues of the homogeneous growing of the shell around the pre-formed seeds. A further indication supporting this idea is given by ${ }^{57} \mathrm{Fe}$ Mössbauer spectroscopy, suitably applied to coupled coreshell nanoparticles and not-coupled ad-hoc mechanical mixtures. Direct proof of the core-shell structure formation is successfully provided by chemical mapping at the nanoscale, by the combination of STEM-EELS, STEM-EDX and STEM-EDX tomography. In particular, STEMEDX is revealed to be a powerful technique to obtain high-quality compositional maps and 3D 
reconstructions of the core-shell heterostructure with sub-nanometer spatial resolution. All the above-findings suggest that the solvothermal seed-mediated growth can be proposed as a powerful and versatile approach to create other classes of heterostructures properly combining magnetic and not-magnetic materials with diverse chemical-physical properties and diverse architectures. These systems can be proposed as heat mediators for magnetic fluid hyperthermia, since the combination of hard (cobalt ferrite) and soft magnetic material (manganese ferrite or spinel iron oxide) in a core-shell architecture, maximizing the contact between the two magnetic phases, allows to improve significantly the performances. ${ }^{24,58}$

\section{METHODS}

Chemicals. Oleic acid (>99.99\%), 1-pentanol (99.89\%), hexane (84.67\%) and toluene (99.26\%) were purchased from Lach-Ner; 1-octanol (>99.99\%) and $\mathrm{Mn}\left(\mathrm{NO}_{3}\right)_{2} \cdot 4 \mathrm{H}_{2} \mathrm{O}(>97.0 \%)$ from SigmaAldrich; absolute ethanol and $\mathrm{Co}\left(\mathrm{NO}_{3}\right)_{2} \cdot 6 \mathrm{H}_{2} \mathrm{O}(99.0 \%)$ from Penta; $\mathrm{NaOH}(>98.0 \%)$ from Fluka; $\mathrm{Fe}\left(\mathrm{NO}_{3}\right)_{3} \cdot 9 \mathrm{H}_{2} \mathrm{O}(98.0 \%)$ from Lachema; $\mathrm{FeCl}_{2} \cdot 4 \mathrm{H}_{2} \mathrm{O}(99 \%)$ from Merck.

Synthesis of $\mathrm{M}^{\mathrm{II}}-\mathrm{Fe}^{\mathrm{III}}$ oleate in 1-pentanol. The mixed $\mathrm{M}^{\mathrm{II}}-\mathrm{Fe}^{\mathrm{III}}$ oleates $\left(\mathrm{M}^{\mathrm{II}}=\mathrm{Co}^{2+}, \mathrm{Mn}^{2+}\right)$ and the $\mathrm{Fe}^{\mathrm{II}}$-oleate were used as metal precursors for the synthesis of $\mathrm{CoFe}_{2} \mathrm{O}_{4}$ or $\mathrm{MnFe}_{2} \mathrm{O}_{4}$ and $\gamma$ $\mathrm{Fe}_{2} \mathrm{O}_{3}$, respectively. They were synthetized and collected following the procedure set up by A. Repko et al. ${ }^{34}$ The molar ratios among the reactants are given in Table 1S for the different metal oleates. First, a pale-yellow sodium oleate solution was prepared in a $250 \mathrm{~mL}$ round-bottom flask dissolving the sodium hydroxide in $10 \mathrm{~mL}$ of distilled water and adding $20 \mathrm{~mL}$ of ethanol together with the oleic acid. Secondly, the iron(III) nitrate and $\mathrm{Me}(\mathrm{II})$ nitrate $\left(\mathrm{M}^{\mathrm{II}}=\mathrm{Co}^{2+}, \mathrm{Mn}^{2+}\right)$ or only iron(II) chloride were dissolved in $10 \mathrm{~mL}$ of distilled water producing an orange solution. This was then added to the sodium oleate one and mechanically stirred in order to obtain the $\mathrm{M}^{\mathrm{II}}-\mathrm{Fe}^{\mathrm{III}}$ oleate or the $\mathrm{Fe}^{\mathrm{II}}$-oleate. After the addition, the formation of the metals oleate complexes made the 
solution black and viscous. The successive addition of $20 \mathrm{~mL}$ of hexane led to a liquid biphasic system, the upper one is the metals oleate containing organic phase while the lower is the water phase. This mixture was boiled under reflux for $60 \mathrm{~min}$ to complete the formation of metals oleate. The as-described procedure was carried out under an inert atmosphere in the case of the $\mathrm{Fe}^{\mathrm{II}}$ oleate synthesis. Then, the system was left to cool down to room temperature. The water phase was removed by Pasteur pipette, while $20 \mathrm{~mL}$ of water, $5 \mathrm{~mL}$ of ethanol and $5 \mathrm{~mL}$ of hexane were added to the organic phase and stirred in order to wash it from the inorganic residuals. The mixture was boiled under reflux for $30 \mathrm{~min}$. This washing step was done twice. Finally, the water phase was completely removed and $15 \mathrm{~mL}$ of 1 -pentanol were added to the flask. The mixture was heated for about $30 \mathrm{~min}$ to induce the complete evaporation of hexane. The obtained product as a viscous black liquid ( $\mathrm{M}^{\mathrm{II}}-\mathrm{Fe}^{\mathrm{III}}$ oleate or $\mathrm{Fe}^{\mathrm{II}}$ oleate in pentanol) was moved into a $40 \mathrm{~mL}$ glass vial with Teflon cup with the help of $5 \mathrm{~mL}$ of 1-pentanol. The composition of the product, i.e. the final amount of pentanol and consequently the concentration of metals oleate was estimated from its weight, assuming quantitative yield from metals salts.

Core: solvothermal preparation of colloidal $\mathrm{CoFe}_{2} \mathrm{O}_{4}$ and $\mathrm{MnFe}_{2} \mathrm{O}_{4}$ nanoparticles. Two samples of $\mathrm{CoFe}_{2} \mathrm{O}_{4}$ nanoparticles of different sizes, labelled as $\mathrm{Co} 1$ and $\mathrm{Co} 2$, and one sample of $\mathrm{MnFe}_{2} \mathrm{O}_{4}$, labelled as $\mathrm{Mn1}$, were prepared by solvothermal hydrolysis of mixed cobalt-iron or manganese-iron oleates in a mixture of organic solvents with different polarities and water contents. The metal oleate was prepared separately, in order to avoid the formation of byproducts. ${ }^{33}$ The formation mechanism of the nanoparticles has been already described by Repko et al. ${ }^{33,34,59}$ In solvothermal condition, water causes the hydrolysis of the oleate and the formation of nanoparticles takes place after nucleation and growth in the organic phase until they reach a critical diameter, which bring them to precipitate. At the end of the treatment, in fact, a black 
precipitate is found at the bottom of the teflon liner, while two liquid phases are present above, an aqueous and an organic one. The water phase is always colourless indicating, as expected, that no particles are present in it. On the contrary, the colour of the organic phase becomes darker with decreasing solvent polarity due to the presence of hydrophobic oleate-capped nanoparticles with a size below the critical diameter necessary to precipitate. The appropriate amount of $\mathrm{M}^{\mathrm{II}}-\mathrm{Fe}$ oleates $\left(\mathrm{M}^{\mathrm{II}}=\mathrm{Co}^{2+}\right.$ or $\mathrm{Mn}^{2+}$, in a 1:2 $\mathrm{M}^{\mathrm{II}}: \mathrm{Fe}^{\mathrm{IIII}}$ ratio to produce $\left.\mathrm{M}^{\mathrm{II}} \mathrm{Fe}_{2} \mathrm{O}_{4}\right)$ in 1-pentanol was moved into a $50 \mathrm{~mL}$ teflon liner and a further amount of a mixture of other solvents (octanol or toluene) was added to reach a total volume of $20 \mathrm{~mL}$, as described in Table $2 \mathrm{~S}$. Then, 10 or $5 \mathrm{~mL}$ of water, depending on the reaction temperature, was added. The solvents and their relative ratios have been chosen according to the study by Repko et al. ${ }^{34}$ in order to prepare particles of different sizes. The liner free space was flushed with nitrogen and was enclosed in a stainless-steel autoclave (Berghof DAB-2), briefly shaken and put vertically into a pre-heated $\left(180^{\circ}\right.$ or $\left.220^{\circ} \mathrm{C}\right)$ oven. The reaction time was 10 hours. After the heat treatment, the autoclave was left to cool down to room temperature, and the as-prepared magnetic nanoparticles were magnetically separated from the supernatant that was discarded. A purification process was conducted twice as follows. First, the particles were dispersed in $10 \mathrm{~mL}$ of hexane (with the help of sonication), then $10 \mathrm{~mL}$ of ethanol were used in order to wash and precipitate the nanoparticles that were finally separated by a magnet. At the end of this step, the nanoparticles were dispersed in $5 \mathrm{~mL}$ of hexane and centrifuged at $3000 \mathrm{rpm}$ for $5 \mathrm{~min}$. In this case the supernatant, which is the desired product, was saved and the precipitate was discarded $(\sim 2 \%)$. The nanoparticles concentration was estimated by sampling an aliquot of the colloidal dispersion, drying it and weighing it. A summary of the synthesis conditions for each sample is reported in Table 2S. It is worthy of note that both the solvent 
polarity (by using 1-octanol or toluene together with 1-pentanol) and the reaction temperature (180 ${ }^{\circ} \mathrm{C}$ or $220{ }^{\circ} \mathrm{C}$ ) play the main role in the nanoparticles growth and their final size.

Core-shell: solvothermal preparation by seed-mediated growth. The $\mathrm{Co} 1, \mathrm{Co} 2$ and $\mathrm{Mn} 1$ nanoparticles were used as seeds to produce core-shell nanostructures by means of a second solvothermal treatment (seed-mediated growth). In particular, for both $\mathrm{Co} 1$ and $\mathrm{Co} 2$, two coreshell samples were prepared with a shell of spinel iron oxide and manganese ferrite, indicated as Cox@Fe and Cox@Mn (where x=1,2), respectively. Moreover, two core-shell samples with a shell of cobalt ferrite and spinel iron oxide were prepared for sample Mn1, labelled as Mn1@Co and Mn1@Fe respectively. Different attempts have been carried out in order to achieve the best experimental conditions, in terms of ratio seeds/shell precursor, solvent, concentration of the precursors, allowing the production of bigger nanoparticles with a narrow size distribution. For example, we found out that 1-octanol is not a suitable solvent because it leads to a high dispersity of the product. This can be probably ascribed to the low colloidal stability of the seed nanoparticles dispersion. Being toluene a good solvent to disperse nanoparticles, it has been chosen instead of

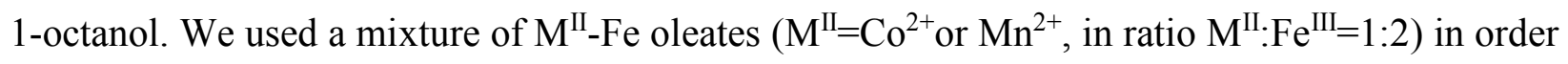
to create a shell of cobalt or manganese ferrite, or $\mathrm{Fe}^{\mathrm{II}}$-oleate in order to create a shell of spinel iron oxide. Indeed, in these experimental conditions, the use of $\mathrm{Fe}^{\mathrm{III}}$ or a mixture of $\mathrm{Fe}^{\mathrm{II}}$ and $\mathrm{Fe}^{\mathrm{III}}$ oleates lead to hematite. The amount of hexane dispersion containing the appropriate quantity of particles (seeds) was added in a teflon liner. The particles were precipitated by adding ethanol in a 1:1 volume ratio with respect to the hexane dispersion, held by a magnet and the liquid was discharged. Then, the particles were dissolved in $10 \mathrm{~mL}$ of toluene (with the help of sonication) and $10 \mathrm{~mL}$ of a 1-pentanol solution of metals oleate was added. Finally, after the addition of $5 \mathrm{~mL}$ of distilled water, the liner was enclosed into the autoclave and treated at $220^{\circ} \mathrm{C}$ for 10 hours. After 
the heat treatment, the purification steps were the same as for the seeds. Table 3S summarises the synthesis conditions for the core-shell nanostructures.

Reference sample: the physical mixture. A reference sample made up of $\mathrm{CoFe}_{2} \mathrm{O}_{4}-\mathrm{MnFe}_{2} \mathrm{O}_{4}$ physical mixture (weight ratio 1:1) was prepared. Both the phases were synthesised as described in the previous paragraph about the cores and the synthesis conditions are shown in Table $2 \mathbf{S}$. Specifically, a proper amount of a hexane dispersion of $\mathrm{CoFe}_{2} \mathrm{O}_{4}$ nanoparticles (Co_mix) was added to the $\mathrm{MnFe}_{2} \mathrm{O}_{4}$ one (Mn_mix), dried and characterized.

Characterization techniques. The chemical composition was studied by Inductively Coupled Plasma - Atomic Emission Spectrometry (ICP-AES). The dried samples were digested by using $\mathrm{HNO}_{3}$. The digested sample solutions were stirred at room temperature for $1 \mathrm{~h}$, then heated up to $\sim 50{ }^{\circ} \mathrm{C}$ for $2 \mathrm{~h}$. The solutions were left to cool down, filtered and diluted by using $1 \% \mathrm{v} / \mathrm{v} \mathrm{HNO}_{3}$ solution. The ICP measurements were made by means of a Liberty 200 ICP Varian spectrometer under the following conditions: Fe line: 259.940 nm, Co line: 238.892 nm, Mn line: 257.610 nm; Fe, Co and Mn concentration range: $(0.1 \div 1.5) \mathrm{ppm}$; Fe detection range: $(0.015 \div 750)$ ppm, Co detection range: $(0.050 \div 2500) \mathrm{ppm}$, Mn detection range: $(0.003 \div 150) \mathrm{ppm}$. The analyses have been repeated two times on different portions of the samples. The chemical formulas were calculated by assuming the absence of anions vacancies.

The samples were characterized by X-ray Diffraction (XRD), using a PANalytical X'Pert PRO

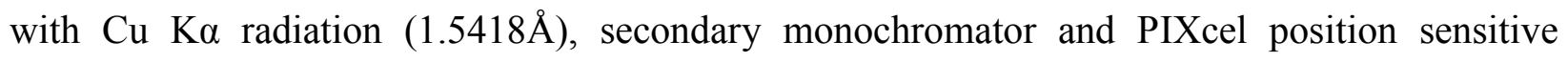
detector. Calibration of peak position and instrumental width was done using powder $\mathrm{LaB}_{6}$ from NIST. The hexane dispersions were dried on a glass plate and measured in the angular range $10^{\circ}$ $90^{\circ}$ with step $0.039^{\circ}$. The analyses of the XRD patterns (identification of the crystalline phase, background subtraction) were done by the PANalytical X'Pert HighScore software. The most 
intense X-ray peaks ((220), (311), (400), (422), (511), (440)) were fitted with Origin Software by PseudoVoigt function, using a 1:1 gaussian:lorentzian ratio $\left(m_{u}=0.5\right)$ :

$y=y_{0}+A\left[m_{u} \frac{2}{\pi} \frac{w}{4\left(x-x_{c}\right)^{2}+w^{2}}+\left(1-m_{u}\right) \frac{\sqrt{4 \ln 2}}{\sqrt{\pi} w} e^{-\frac{4 \ln 2}{w^{2}}\left(x-x_{c}\right)^{2}}\right]$

In reciprocal space

$q=\frac{2 \sin \theta}{\lambda}=\frac{\sqrt{h^{2}+k^{2}+l^{2}}}{a}$

The crystallite size (diameter) was obtained from full width at half maximum of q (denoted as $\left.\Gamma_{\mathrm{q}}\right)$ by

$$
d=\frac{1.10}{\Gamma_{q}} 34
$$

Room temperature ${ }^{57} \mathrm{Fe}$ Mössbauer spectroscopy was done on Wissel spectrometer using transmission arrangement and proportional detector LND-45431. A $\alpha$-Fe foil was used as a standard, and fitting procedure was done by NORMOS program to determine the isomer shift, quadrupole splitting, hyperfine field and full width at half maximum of the signals.

TEM images were obtained by using a JEOL 200CX operating at $200 \mathrm{kV}$. The particle size distribution was obtained by measuring in the automatic mode over 1000 particles by means of the software Pebbles and adopting a spherical shape. ${ }^{60}$ The mean particle diameter was calculated as the average value and the dispersity as the percent ratio between the standard deviation and the average value.

HRTEM images were carried out using JEOL JEM 2010 UHR equipped with a Gatan imaging filter (GIF) and a 794-slow scan CCD camera.

EDX measurements were carried out in the STEM mode using a FEI Talos F200X with a fieldemission gun operating at $200 \mathrm{kV}$ equipped with a four-quadrant 0.9 -sr energy dispersive X-ray spectrometer. 3D tomography was acquired in STEM-EDX mode with tilt series from $-70^{\circ}$ to $70^{\circ}$ 
and $10^{\circ}$ intervals. The single line profiles have been calculated using the Matlab command "improfile" for different sections all over a particle (i.e. over $360^{\circ}$ with a step of 0.1 and the results averaged.

EELS and HRSTEM measurements were carried out using an aberration-corrected scanning transmission electron microscope (Hitachi HD2700C) with a cold field emission gun operating at $200 \mathrm{kV}$ equipped with a parallel EELS spectrometer (high resolution Enfina).

Transform Infrared Spectroscopy (FT-IR) spectra were recorded in the region from 350 to 4000

$\mathrm{cm}^{-1}$ by using a Bruker Vertex 70 spectrophotometer on the colloidal dispersions by means of a Platinum ATR Unit A 225, (standard ATR crystal material: diamond).

TGA curves were obtained on powders by using a Mettler-Toledo TGA/SDTA 851 in the 25$1000^{\circ} \mathrm{C}$ range, with a heating rate of $10^{\circ} \mathrm{C} / \mathrm{min}$ under $50 \mathrm{~mL} / \mathrm{min} \mathrm{O}_{2}$ flow.

\section{AUTHOR INFORMATION}

\section{Corresponding Authors}

*E-mail (CC) ccannas@unica.it

*E-mail (HLX) hxin@bnl.gov

\section{ACKNOWLEDGEMENTS}

University of Cagliari is acknowledged for the grant financing for Marco Sanna Angotzi. Consorzio AUSI (Consorzio per la promozione delle Attività Universitarie del Sulcis-Iglesiente) is acknowledged for the grants of A. Ardu and C. Cara. This research used resources of the Center for Functional Nanomaterials, which is a U.S. DOE Office of Science Facility, at Brookhaven National Laboratory under Contract No. DE-SC0012704.

\section{ASSOCIATED CONTENT}


The Supporting Information is available free of charge on the ACS Publications website.

Synthesis conditions for different metal oleates; synthesis condition for the pure spinel ferrite nanoparticles; synthesis condition for the core-shell nanoparticles; empirical formulas for core and core-shell samples obtained from ICP-AES; shell thicknesses of the samples calculated from TEM, STEM-EDX and STEM-EELS; FT-IR spectra of the samples; assignment of FT-IR bands of the samples; TGA curves of the samples; computation of capping molecule packing on the nanoparticles surface.

\section{REFERENCES}

(1) López-Ortega, A.; Estrader, M.; Salazar-Alvarez, G.; Roca, A. G.; Nogués, J. Applications of Exchange Coupled Bi-Magnetic Hard/Soft and Soft/Hard Magnetic Core/shell Nanoparticles. Phys. Rep. 2015, 553, 1-32.

(2) Chaudhuri, R. G.; Paria, S. Core/Shell Nanoparticles : Classes, Properties, Synthesis Mechanisms, Characterization, and Applications. Chem. Rev. 2012, 112, 2373-2433.

(3) Liu, F.; Hou, Y.; Gao, S. Exchange-Coupled Nanocomposites: Chemical Synthesis, Characterization and Applications. Chem. Soc. Rev. 2014, 43, 8098-8113.

(4) Magnetic Nanoparticles: From Fabrication and Clinical Applications; Thanh, N. T. K., Ed.; CRC Press,.; 2012.

(5) Meiklejohn, W. H.; Bean, C. P. New Magnetic Anisotropy. Phys. Rev. 1957, 105, 904-913.

(6) Lo, A.; Tobia, D.; Winkler, E.; Golosovsky, I. V; Gonza, M. A.; Surin, S.; Arbiol, J.; Peiro, F.; Zysler, R. D.; Baro, M. D.; Nogue, J. Size-Dependent Passivation Shell and Magnetic Properties in Antiferromagnetic/Ferrimagnetic Core/Shell $\mathrm{MnO}$ Nanoparticles. J. Am. Chem. Soc. 2002, 132, 9398-9407.

(7) Kavich, D. W.; Dickerson, J. H.; Mahajan, S. V.; Hasan, S. A.; Park, J. H. Exchange Bias 
of Singly Inverted $\mathrm{FeO} / \mathrm{Fe}_{3} \mathrm{O}_{4}$ Core-Shell Nanocrystals. Phys. Rev. B - Condens. Matter Mater. Phys. 2008, 78, 1-6.

(8) Winkler, E. L.; Lima, E.; Tobia, D.; Saleta, M. E.; Troiani, H. E.; Agostinelli, E.; Fiorani, D.; Zysler, R. D. Origin of Magnetic Anisotropy in $\mathrm{ZnO} / \mathrm{CoFe}_{2} \mathrm{O}_{4}$ and $\mathrm{CoO} / \mathrm{CoFe}_{2} \mathrm{O}_{4}$ Core/shell Nanoparticle Systems. Appl. Phys. Lett. 2012, 101, 2-6.

(9) Lottini, E.; López-Ortega, A.; Bertoni, G.; Turner, S.; Meledina, M.; Tendeloo, G. Van; De Julián Fernández, C.; Sangregorio, C. Strongly Exchange Coupled Core|Shell Nanoparticles with High Magnetic Anisotropy: A Strategy toward Rare-Earth-Free Permanent Magnets. Chem. Mater. 2016, 28, 4214-4222.

(10) Cannas, C.; Musinu, a.; Peddis, D.; Piccaluga, G. Synthesis and Characterization of $\mathrm{CoFe}_{2} \mathrm{O}_{4}$ Nanoparticles Dispersed in a Silica Matrix by a Sol-Gel Autocombustion Method. Chem. Mater. 2006, 18, 3835-3842.

(11) Fantechi, E.; Innocenti, C.; Albino, M.; Lottini, E.; Sangregorio, C. Influence of Cobalt Doping on the Hyperthermic Efficiency of Magnetite Nanoparticles. J. Magn. Magn. Mater. 2015, 380, 365-371.

(12) Mameli, V.; Musinu, A.; Ardu, A.; Ennas, G.; Peddis, D.; Niznansky, D.; Sangregorio, C.; Innocenti, C.; Thanh, N. T. K.; Cannas, C. Studying the Effect of Zn-Substitution on the Magnetic and Hyperthermic Properties of Cobalt Ferrite Nanoparticles. Nanoscale 2016, 8 , $10124-10137$.

(13) Sun, S.; Zeng, H.; Robinson, D. B.; Raoux, S.; Rice, P. M.; Wang, S. X.; Li, G. Monodisperse $\mathrm{MFe}_{2} \mathrm{O}_{4}(\mathrm{M}=\mathrm{Fe}, \mathrm{Co}, \mathrm{Mn})$ Nanoparticles. J. Am. Chem. Soc. 2004, 126, $273-$ 279.

(14) Niederberger, M.; Pinna, N. Metal Oxide Nanoparticles in Organic Solvents. Synthesis, 
Formation, Assembly and Application; Springer, 2009.

(15) Cannas, C.; Musinu, A.; Ardu, A.; Orrù, F.; Peddis, D.; Casu, M.; Sanna, R.; Angius, F.; Diaz, G.; Piccaluga, G. $\mathrm{CoFe}_{2} \mathrm{O}_{4}$ and $\mathrm{CoFe}_{2} \mathrm{O}_{4} / \mathrm{SiO}_{2}$ Core/Shell Nanoparticles: Magnetic and Spectroscopic Study. Chem. Mater. 2010, 22, 3353-3361.

(16) Cannas, C.; Ardu, A.; Peddis, D.; Sangregorio, C.; Piccaluga, G.; Musinu, A. SurfactantAssisted Route to Fabricate $\mathrm{CoFe}_{2} \mathrm{O}_{4}$ Individual Nanoparticles and Spherical Assemblies. J. Colloid Interface Sci. 2010, 343, 415-422.

(17) Carla Cannas, Andrea Ardu Anna Musinu,Lorenza Suber, Gabriele Ciasca, Heinz Amenitsch, and G. C. Hierarchical Formation Mechanism of $\mathrm{CoFe}_{2} \mathrm{O}_{4}$ Mesoporous Assemblies. ACS Nano 2015, 9, 7277-7286.

(18) Lee, J.-H.; Jang, J.-T.; Choi, J.-S.; Moon, S. H.; Noh, S.-H.; Kim, J.-G. J.-W. J.-G. J.-W.; Kim, J.-G. J.-W. J.-G. J.-W.; Kim, I.-S.; Park, K. I.; Cheon, J. Exchange-Coupled Magnetic Nanoparticles for Efficient Heat Induction. Nat. Nanotechnol. 2011, 6, 418-422.

(19) Song, Q.; Zhang, Z. J. Controlled Synthesis and Magnetic Properties of Bimagnetic Spinel Ferrite $\mathrm{CoFe}_{2} \mathrm{O}_{4}$ and $\mathrm{MnFe}_{2} \mathrm{O}_{4}$ Nanocrystals with Core-Shell Architecture. J. Am. Chem. Soc. 2012, 134, 10182-10190.

(20) Thanh, N. T. K.; Maclean, N.; Mahiddine, S. Mechanisms of Nucleation and Growth of Nanoparticles in Solution. Chem. Rev. 2014, 114, 7610-7630.

(21) Xia, Y.; Gilroy, K. D.; Peng, H.-C.; Xia, X. Seed-Mediated Growth of Colloidal Metal Nanocrystals. Angew. Chemie Int. Ed. 2017, 56, 60-95.

(22) Zeng, H.; Sun, S.; Li, J.; Wang, Z. L.; Liu, J. P. Bimagnetic Core/Shell FePt $/ \mathrm{Fe}_{3} \mathrm{O}_{4}$ Nanoparticles. Nano Lett. 2004, 4, 187-190.

(23) Masala, O.; Hoffman, D.; Sundaram, N.; Page, K.; Proffen, T.; Lawes, G.; Seshadri, R. 
Preparation of Magnetic Spinel Ferrite Core/Shell Nanoparticles: Soft Ferrites on Hard Ferrites and Vice Versa. Solid State Sci. 2006, 8, 1015-1022.

(24) Noh, S.-H. H.; Na, W.; Jang, J.-T. T.; Lee, J.-H. H.; Lee, E. J.; Moon, S. H.; Lim, Y.; Shin, J. S.; Cheon, J. Nanoscale Magnetism Control via Surface and Exchange Anisotropy for Optimized Ferrimagnetic Hysteresis. Nano Lett. 2012, 12, 3716-3721.

(25) López-Ortega, a; Estrader, M.; Salazar-Alvarez, G.; Estradé, S.; Golosovsky, I. V; Dumas, R. K.; Keavney, D. J.; Vasilakaki, M.; Trohidou, K. N.; Sort, J.; Peiró, F.; Suriñach, S.; Baró, M. D.; Nogués, J. Strongly Exchange Coupled Inverse Ferrimagnetic Soft/Hard, $\mathrm{Mn}_{(\mathrm{x})} \mathrm{Fe}_{(3-\mathrm{x})} \mathrm{O}_{4} / \mathrm{Fe}_{(\mathrm{x})} \mathrm{Mn}_{(3-\mathrm{x})} \mathrm{O}_{4}$, Core/Shell Heterostructured Nanoparticles. Nanoscale 2012, $4,5138-5147$.

(26) Chen, J.; Ye, X.; Oh, S. J.; Kikkawa, J. M.; Kagan, C. R.; Murray, C. B. Bistable Magnetoresistance Switching in Exchange-Coupled $\mathrm{CoFe}_{2} \mathrm{O}_{4}-\mathrm{Fe}_{3} \mathrm{O}_{4}$ Binary Nanocrystal Superlattices by Self-Assembly and Thermal Annealing. ACS Nano 2013, 7, 1478-1486.

(27) Estrader, M.; López-Ortega, A.; Estradé, S.; Golosovsky, I. V.; Salazar-Alvarez, G.; Vasilakaki, M.; Trohidou, K. N.; Varela, M.; Stanley, D. C.; Sinko, M.; Pechan, M. J.; Keavney, D. J.; Peiró, F.; Suriñach, S.; Baró, M. D.; Nogués, J. Robust Antiferromagnetic Coupling in Hard-Soft Bi-Magnetic Core/shell Nanoparticles. Nat. Commun. 2013, 4, 2960.

(28) Gavrilov-Isaac, V.; Neveu, S.; Dupuis, V.; Taverna, D.; Gloter, A.; Cabuil, V. Synthesis of Trimagnetic Multishell $\mathrm{MnFe}_{2} \mathrm{O}_{4} @ \mathrm{CoFe}_{2} \mathrm{O}_{4} @ \mathrm{NiFe}_{2} \mathrm{O}_{4}$ Nanoparticles. Small 2015, 11, 2614-2618.

(29) Gomes, J. D. a; Sousa, M. H.; Tourinho, F. a.; Aquino, R.; Da Silva, G. J.; Depeyrot, J.; Dubois, E.; Perzynski, R. Synthesis of Core-Shell Ferrite Nanoparticles for Ferrofluids: Chemical and Magnetic Analysis. J. Phys. Chem. C 2008, 112, 6220-6227. 
(30) Honarbakhsh-Raouf, A.; Emamian, H. R.; Yourdkhani, A.; Ataie, A. Synthesis And Characterization Of $\mathrm{CoFe}_{2} \mathrm{O}_{4} / \mathrm{Ni}_{0.5} \mathrm{Zn}_{0.5} \mathrm{Fe}_{2} \mathrm{O}_{4}$ Core/Shell Magnetic Nanocomposite By The Wet Chemical Route. Int. J. Mod. Phys. B 2010, 24, 5807-5814.

(31) Wang, J.; Zhou, Z.; Wang, L.; Wei, J.; Yang, H.; Yang, S.; Zhao, J. $\mathrm{CoFe}_{2} \mathrm{O}_{4} @ \mathrm{MnFe}_{2} \mathrm{O}_{4} /$ Polypyrrole Nanocomposites for in Vitro Photothermal/Magnetothermal Combined Therapy. RSC Adv. 2015, 5, 7349-7355.

(32) Aliofkhazraei, M. Handbook of Nanoparticles. Handb. Nanoparticles 2015, 1-1426.

(33) Repko, A.; Nižňanský, D.; Poltierová-Vejpravová, J. A Study of Oleic Acid-Based Hydrothermal Preparation of $\mathrm{CoFe}_{2} \mathrm{O}_{4}$ Nanoparticles. J. Nanoparticle Res. 2011, 13, 50215031.

(34) Repko, A.; Vejpravová, J.; Vacková, T.; Zákutná, D.; Nižňanský, D. Oleate-Based Hydrothermal Preparation of $\mathrm{CoFe}_{2} \mathrm{O}_{4}$ Nanoparticles, and Their Magnetic Properties with Respect to Particle Size and Surface Coating. J. Magn. Magn. Mater. 2015, 390, 142-151.

(35) Cara, C.; Musinu, A.; Mameli, V.; Ardu, A.; Niznansky, D.; Bursik, J.; Scorciapino, M. a.; Manzo, G.; Cannas, C. Dialkylamide as Both Capping Agent and Surfactant in a Direct Solvothermal Synthesis of Magnetite and Titania Nanoparticles. Cryst. Growth Des. 2015, $15,2364-2372$.

(36) Almeida, T. P.; Moro, F.; Fay, M. W.; Zhu, Y.; Brown, P. D. Tuneable Magnetic Properties of Hydrothermally Synthesised Core/Shell $\mathrm{CoFe}_{2} \mathrm{O}_{4} / \mathrm{NiFe}_{2} \mathrm{O}_{4}$ and $\mathrm{NiFe}_{2} \mathrm{O}_{4} / \mathrm{CoFe}_{2} \mathrm{O}_{4}$ Nanoparticles. J. Nanoparticle Res. 2014, 16, 1-13.

(37) Sattar, A. A.; EL-Sayed, H. M.; ALsuqia, I. Structural and Magnetic Properties of $\mathrm{CoFe}_{2} \mathrm{O}_{4} / \mathrm{NiFe}_{2} \mathrm{O}_{4}$ Core/Shell Nanocomposite Prepared by the Hydrothermal Method. $J$. Magn. Magn. Mater. 2015, 395, 89-96. 
(38) van Ewijk, G. A.; Vroege, G. J.; Philipse, A. P. Convenient Preparation Methods for Magnetic Colloids. J. Magn. Magn. Mater. 1999, 201, 31-33.

(39) Gnanaprakash, G.; Philip, J.; Jayakumar, T.; Raj, B. Effect of Digestion Time and Alkali Addition Rate on Physical Properties of Magnetite Nanoparticles. J. Phys. Chem. B 2007, $111,7978-7986$.

(40) Ayyappan, S.; Gnanaprakash, G.; Panneerselvam, G.; Antony, M. P.; Philip, J. Effect of Surfactant Monolayer on Reduction of $\mathrm{Fe}_{3} \mathrm{O}_{4}$ Nanoparticles under Vacuum. J. Phys. Chem. C 2008, 112, 18376-18383.

(41) Murad, E.; Johnston, J. H. Iron Oxides and Oxyhydroxides. Mössbauer Spectroscopy Applied to Inorganic Chemistry, 1987, 507-583.

(42) Cranshaw, T. E. Mössbauer Spectroscopy. J. Phys. E. 1974, 7, 497.

(43) Duarte, J. M. G.; Campbell, S. L. Mössbauer Spectroscopy. Design 2009, 2142, 3-7.

(44) Fultz, B. Mössbauer Spectrometry. Charact. Mater. 2011.

(45) Coey, J. M. D. Magnetism and Magnetic Materials; 2009; Vol. 12.

(46) Zuo, X.; He, Y.; Yang, A.; Bernardo, B.; Harris, V. G.; Vittoria, C. Calculation of Exchange Constants in Spinel Ferrites with Magnetic S-State Ions. J. Appl. Phys. 2005, 97, 20052007.

(47) Han, L.; Meng, Q.; Wang, D.; Zhu, Y.; Wang, J.; Du, X.; Stach, E. A.; Xin, H. L. Interrogation of Bimetallic Particle Oxidation in Three Dimensions at the Nanoscale. Nat. Commun. 2016, 7, 13335.

(48) Wang, D.; Liu, S.; Wang, J.; Lin, R.; Kawasaki, M.; Rus, E.; Silberstein, K. E.; Lowe, M. A.; Lin, F.; Nordlund, D. Liu, H.; Muller, D. A.; Xin, H. L.; Abruña, H. D.; Spontaneous Incorporation of Gold in Palladium-Based Ternary Nanoparticles Makes Durable 
Electrocatalysts for Oxygen Reduction Reaction. Nat. Commun. 2016, 7, 11941.

(49) Wang, D.; He, H.; Han, L.; Lin, R.; Wang, J.; Wu, Z.; Liu, H.; Xin, H. L. Three-Dimensional Hollow-Structured Binary Oxide Particles as an Advanced Anode Material for High-Rate and Long Cycle Life Lithium-Ion Batteries. Nano Energy 2016, 20, 212-220.

(50) Schlossmacher, P.; Klenov, D. O.; Freitag, B.; Harrach, S. Von; Steinbach, A. Nanoscale Chemical Compositional Analysis with an Innovative S/TEM-EDX System. Microsc. Anal. Nanotechnol. Suppl. 2010, 24, S5-S8.

(51) Schlossmacher, P.; Klenov, D. O.; Freitag, B.; von Harrach, H. S. Enhanced Detection Sensitivity with a New Windowless XEDS System for AEM Based on Silicon Drift Detector Technology. Micros. Today 2010, 18, 14-20.

(52) Harrach, H. S. Von; Dona, P.; Freitag, B.; Soltau, H.; Niculae, A.; Rohde, M. An Integrated Silicon Drift Detector System for FEI Schottky Field. Microsc. Microanal. 2009, 15, 8-9.

(53) Allen, L. J.; D’Alfonso, A. J.; Freitag, B.; Klenov, D. O. Chemical Mapping at Atomic Resolution Using Energy-Dispersive X-Ray Spectroscopy. MRS Bull. 2012, 37, 47-52.

(54) Kothleitner, G.; Neish, M. J.; Lugg, N. R.; Findlay, S. D.; Grogger, W.; Hofer, F.; Allen, L. J. Quantitative Elemental Mapping at Atomic Resolution Using X-Ray Spectroscopy. Phys. Rev. Lett. 2014, 112, 1-5.

(55) Gomes, J. a.; Azevedo, G. M.; Depeyrot, J.; Mestnik-Filho, J.; Paula, F. L. O.; Tourinho, F. a.; Perzynski, R. Structural, Chemical, and Magnetic Investigations of Core-Shell Zinc Ferrite Nanoparticles. J. Phys. Chem. C 2012, 116, 24281-24291.

(56) Tang, Z. X.; Sorensen, C. M.; Klabunde, K. J.; Hadjipanayis, G. C. Preparation of Manganese Ferrite Fine Particles from Aqueous Solution. J. Colloid Interface Sci. 1991, 146, 38-52. 
(57) Gnanaprakash, G.; Philip, J.; Raj, B. Effect of Divalent Metal Hydroxide Solubility Product on the Size of Ferrite Nanoparticles. Mater. Lett. 2007, 61, 4545-4548.

(58) Lee, J.-H.; Jang, J.; Choi, J.; Moon, S. H.; Noh, S.; Kim, J.-G. J.; Kim, J.-G. J.; Kim, I.-S.; Park, K. I.; Cheon, J. Exchange-Coupled Magnetic Nanoparticles for Efficient Heat Induction. Nat Nano 2011, 6, 418-422.

(59) Repko, A.; Nižňanský, D.; Matulková, I.; Kalbáč, M.; Vejpravová, J. Hydrothermal Preparation of Hydrophobic and Hydrophilic Nanoparticles of Iron Oxide and a Modification with CM-Dextran. J. Nanoparticle Res. 2013, 15, 1-9.

(60) Mondini, S.; Ferretti, a. M.; Puglisi, a.; Ponti, a. Pebbles and PebbleJuggler: Software for Accurate, Unbiased, and Fast Measurement and Analysis of Nanoparticle Morphology from Transmission Electron Microscopy (TEM) Micrographs. Nanoscale 2012, 4, 5356.

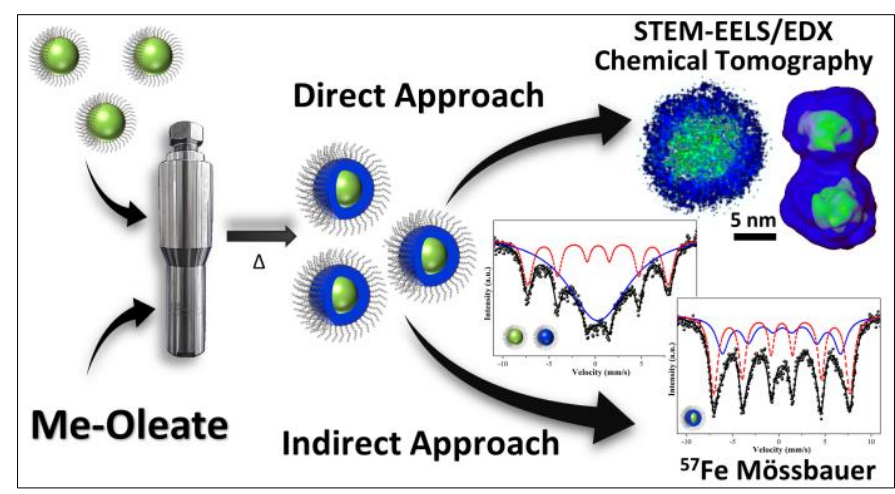




\section{DISCLAIMER}

This report was prepared as an account of work sponsored by an agency of the United States Government. Neither the United States Government nor any agency thereof, nor any of their employees, nor any of their contractors, subcontractors, or their employees, makes any warranty, express or implied, or assumes any legal liability or responsibility for the accuracy, completeness, or any third party's use or the results of such use of any information, apparatus, product, or process disclosed, or represents that its use would not infringe privately owned rights. Reference herein to any specific commercial product, process, or service by trade name, trademark, manufacturer, or otherwise, does not necessarily constitute or imply its endorsement, recommendation, or favoring by the United States Government or any agency thereof or its contractors or subcontractors. The views and opinions of authors expressed herein do not necessarily state or reflect those of the United States Government or any agency thereof. 